\title{
Indústria e Desenvolvimento Econômico nas Regiões Brasileiras: Revisitando Hipóteses da Desindustrialização "Natural" com Dados Municipais (1999 a 2011)*
}

\section{Industry and Economic Development of the Brazilian Regions: Revisiting "Natural" Deindustrialization Hypothesis with Municipal Data (1999-2011)}

\author{
Carlos César Santejo Saiani** \\ Michele Polline Veríssimo***
}

\begin{abstract}
Resumo: Este artigo investiga a hipótese de desindustrialização "natural" no Brasil, com o objetivo de avaliar a existência e as implicações da relação no formato de um "U-invertido" entre as participações industriais no emprego e no produto e a renda per capita dos municípios brasileiros, segmentados em regiões geográficas. Para isso, são realizadas estimações econométricas em painel por efeitos fixos e pelo método Tobit (robustez). As evidências encontradas não refutam quatro hipóteses levantadas pela literatura: ocorrência do "U-invertido" na relação entre a industrialização (medida pelo emprego e pelo produto) e a renda per capita municipal; redução da participação industrial no emprego em nível de renda inferior ao ponto de retração da participação industrial no produto; queda da participação da indústria no produto nas regiões menos desenvolvidas em níveis de renda inferiores (precoces) ao do Sudeste; e aumento da importância relativa do setor de serviços em detrimento à da indústria.
\end{abstract}

Palavras-chave: Desindustrialização "natural”. Desenvolvimento. Dados em painel.

Abstract: This paper investigates the "natural" de-industrialization hypothesis in Brazil, aiming to evaluate the existence and implications of the "U-inverted" relationship between employment and product industrial participation and per capita income municipalities, segmented into geographical regions. For this, they are performed econometric estimates by panel with fixed effects and Tobit panel. The results suggest four important and consistent evidences with the literature hypotheses about the subject: the occurrence of the "U-inverted" relationship between the degree of industrialization and per capita income level; the loss of employment industrial participation in a lower income level to product industrial decrease point; the reduction of product industrial participation in less developed regions in per capita income levels lower than those observed in the Southeast (more developed region); the increase in the relative importance of the service sector to the detriment of industry.

* Os autores agradecem o apoio do CNPq e da FAPEMIG.

** Doutor em Economia pela Escola de Economia de São Paulo da Fundação Getúlio Vargas (EESP/ FGV). Professor adjunto do Instituto de Economia e Relações Internacionais da Universidade Federal de Uberlândia (UFU). E-mail: ssaiani@ufu.br

*** Doutora em Economia pela Universidade Federal de Uberlândia (UFU). Professora adjunta do Instituto de Economia e Relações Internacionais da Universidade Federal de Uberlândia (UFU). E-mail: micheleverissimo@ufu.br 
Keywords: Natural de-industrialization. Development. Panel Data.

JEL Classification: L60; O14; R19.

\section{Introdução}

A industrialização é defendida por seus potenciais impactos positivos sobre a economia, tais como efeitos de encadeamento nas cadeias produtivas, para frente e para trás, mais fortes do que os de outros setores; economias estáticas e dinâmicas de escala que tornam a produtividade na indústria função crescente da produção, o que é fundamental ao crescimento econômico no longo prazo; por ser o setor que mais induz e difunde o progresso tecnológico; maiores elasticidades-renda das importações de produtos industriais do que as de commodities e bens primários, o que torna a expansão da indústria fundamental para aliviar restrições do balanço de pagamentos ao crescimento. A industrialização, portanto, influencia positivamente o crescimento efetivo e potencial, gerando retornos crescentes e progresso tecnológico e reduzindo restrições externas (KALDOR, 1966; OREIRO; FEIJÓ, 2010).

Consequentemente, a desindustrialização é uma preocupação recorrente nos debates políticos e acadêmicos. A literatura econômica aponta alguns conceitos (e/ou causas) para esse processo, dentre os quais o de desindustrialização "natural", que corresponde à potencial perda de participação relativa da indústria (no produto e no emprego) frente à expansão do setor de serviços à medida que as economias atingem estágios mais avançados de desenvolvimento, medido pela renda per capita. A desindustrialização também pode ser "induzida" por políticas liberalizantes (abertura comercial e financeira, por exemplo) que afetem o desempenho da indústria e façam a economia retroceder a uma especialização ricardiana intensiva em recursos naturais ou à reprimarização. Outra possibilidade é que a desindustrialização decorra de uma apreciação cambial concomitante à elevação dos preços de commodities ou à descoberta de novas reservas de recursos naturais ("doença holandesa"), que desestimulam a inserção internacional de manufaturados e, assim, inibem as atividades industriais.

Embora não haja consenso, alguns estudos defendem que há uma desindustrialização em curso na economia brasileira. A causa também é um ponto de divergência. Carvalho e Kupfer (2007), por exemplo, defendem que a indústria do país se especializou em setores de menor conteúdo tecnológico e em um nível de renda menor do que o verificado em outras economias, como Estados Unidos da América, Austrália, Canadá, Coreia do Sul e Taiwan, sugerindo uma desindustrialização precoce no Brasil. Para Bresser-Pereira (2007) e Oreiro e Feijó (2010), o país sofre uma desindustrialização em decorrência de uma "doença holandesa". 
Já para Cano (2012), políticas macroeconômicas, como câmbio apreciado, abertura comercial, juros elevados e investimentos externos concentrados nos serviços, contribuem para a queda da importância relativa da indústria. Por outro lado, Feijó, Carvalho e Almeida (2005), Nakahodo e Jank (2006) e Nassif (2008), entre outros, contestam, em algum grau, que o país passa por uma desindustrialização ou, pelo menos, que esta não possa ser um processo "natural".

Apesar de existirem vários trabalhos que realizam análises com dados agregados para o Brasil, poucos avaliam, com informações municipais, a ocorrência de desindustrialização "natural" nas suas diferentes regiões. Ou seja, se, nos municípios, as participações da indústria no produto e no emprego se relacionam aos estágios de desenvolvimento econômico, mensurado pelo nível de renda per capita. Este estudo contribui para o preenchimento de tal lacuna na literatura. Por meio de estimações econométricas para um painel de todos os municípios brasileiros com dados disponíveis referentes ao período de 1999 a 2011, são testadas quatro hipóteses inter-relacionadas levantadas pela literatura:

(i) as relações entre as participações industriais no emprego e no produto e os níveis de renda per capita teriam o formato de um "U-invertido"; ou seja, a importância relativa da indústria aumentaria até certo nível de desenvolvimento, a partir do qual passaria a diminuir;

(ii) em função da produtividade do trabalho tender a crescer mais rapidamente na indústria do que em outros setores, a participação industrial no emprego diminuiria "antes" (ou seja, em nível de renda per capita inferior) do que a participação industrial no produto;

(iii) em regiões menos desenvolvidas, a redução da participação relativa da indústria tende a se dar em níveis de renda per capita (turning points) inferiores aos observados nas regiões mais desenvolvidas, o que sinaliza uma desindustrialização "precoce" ("prematura") nas primeiras;

(iv) a redução da participação relativa da indústria, a partir de determinado nível de renda per capita, se daria em função do avanço da participação relativa do setor de serviços.

As estimações são realizadas para o Brasil e para cada uma de suas grandes regiões geográficas (Sudeste, Norte, Nordeste, Centro-Oeste e Sul). Antecipada e resumidamente, as evidências obtidas são relativamente robustas para corroborar as quatro hipóteses ou, pelo menos, para não as refutar integralmente. No Brasil e em todas as suas regiões, observa-se a relação em "U-invertido" para as participações industriais no emprego e no produto municipais. Os turning points do emprego formal são inferiores aos do produto em todas as regiões e no país. Ademais, os resultados sinalizam que a redução da participação industrial a partir de certo nível de renda se dá com avanço dos serviços. Assim, a convergência desses resultados sugere que a desindustrialização nos municípios brasileiros, ao menos 
em parte, pode ser um processo "natural" associado ao grau de desenvolvimento. As evidências também sinalizam que, na participação industrial no produto, as desindustrializações nos municípios das regiões menos desenvolvidas podem ser "precoces" comparativamente ao Sudeste; na participação industrial no emprego, somente para a região Norte existem indícios da precocidade.

Antes de iniciar o estudo, algumas ressalvas são importantes. Primeiramente, vale ressaltar que evidências de desindustrialização "natural" nos municípios brasileiros não refutam a possibilidade de ocorrência de desindustrialização "induzida" no país como um todo, por "doença holandesa" ou por políticas. Na verdade, sinalizam somente que, no nível municipal, a desindustrialização pode ser um processo "natural" atrelado à dinâmica da renda. Da mesma forma, não significa que a indústria foi ultrapassada pelos serviços como o setor que mais gera crescimento. Nesse sentido, pode-se apontar como ilustrativo o trabalho de Szirmai e Verspagen (2011) que, analisando 88 países no período de 1950 a 2005, constatam efeitos positivos da indústria sobre o crescimento, mas não dos serviços.

Outra ressalva refere-se ao reconhecimento de que o conceito de desenvolvimento econômico envolve, para além da análise do nível de renda per capita, mais atrelada à dinâmica do crescimento econômico, aspectos mais amplos relacionados ao bem-estar da sociedade, como fatores sociais e de distribuição de renda. Porém, no geral, a literatura sobre desindustrialização "natural" considera a renda per capita como proxy para o desenvolvimento. Assim, sendo coerente com a literatura, este estudo utiliza a nomenclatura desenvolvimento econômico para se referir ao nível de renda per capita. Também em coerência com a literatura, emprega-se o termo "precoce" (ou "prematuro") para a perda da participação relativa da indústria em uma região em nível de renda per capita inferior ao Sudeste, região que concentra grande parte das atividades industriais brasileiras. Tomar algum local como referência para a atribuição de precocidade é prática comum na literatura, mas é importante ter em mente que são necessários outros parâmetros para concluir se representa um processo negativo à economia.

Tais aspectos são retomados ao longo do artigo, que, além dessa introdução e das considerações finais, divide-se em outras cinco seções. A segunda sumariza a literatura teórica sobre conceitos e causas da desindustrialização, destacando hipóteses associadas à de processo "natural". A terceira sistematiza evidências existentes na literatura para o referido processo em termos regionais no Brasil. Essa sistematização é uma contribuição secundária do artigo, pois não foi encontrado outro que tenha feito o mesmo. A quarta apresenta uma breve análise descritiva para avaliar se, nos anos 2000, com dados municipais agregados, há evidências de desindustrialização. Estas podem se somar a outras já existentes na literatura para a avaliação da variação da participação industrial no emprego e produto no Brasil e nas regiões, assim como se persiste a tendência das décadas anteriores de des- 
concentração regional da indústria brasileira, o que também é evidenciado pela literatura, conforme é comentado na terceira seção. A análise descritiva constitui, então, outra contribuição secundária deste estudo. A quinta seção discute as estratégias empíricas para testar as hipóteses, baseadas em estimações em painel com efeitos fixos e, para averiguar a robustez dos resultados frente à censura de dados nas variáveis dependentes, pelo método Tobit em painel. Na sexta seção, os resultados são analisados.

\section{Desindustrialização: Conceitos e Hipóteses}

Pelo conceito original, desenvolvido por Rowthorn e Wells (1987) e Rowthorn e Ramaswamy (1997), desindustrialização é um processo de retração significativa e persistente da participação da indústria no emprego total da economia. Tregenna (2009), por sua vez, propõe um conceito ampliado para desindustrialização, definindo-a como um processo de reduções concomitantes das participações industriais no emprego total e no produto. Para a autora, a definição de desindustrialização em termos apenas de emprego é limitada devido a diversos fatores. Por exemplo, um aumento da produtividade da indústria superior à do setor de serviços pode provocar desindustrialização somente pelo emprego.

Assim, conforme ressalta Nassif (2008), o ritmo da produtividade industrial é uma das possíveis explicações para a queda da participação da indústria no emprego. Ou seja, a desindustrialização seria "paradoxalmente" um fenômeno tecnológico, por se tratar do setor econômico tido como o que mais induz inovações tecnológicas. Já Rowthorn e Ramaswamy (1997) apontam que a demanda por produtos manufaturados pode ser afetada por mudanças nas exportações, reduções nos investimentos e terceirizações de atividades manufatureiras, que passam a ser classificadas como de serviços - fenômeno que é conhecido como "ilusão estatística”. Tais fatores contribuem para a redução da participação industrial no emprego total, mas não, necessariamente, no produto. Consequentemente, também enfraquecem a constatação de uma desindustrialização somente pela dimensão do emprego.

Fundamentando-se em uma generalização da Lei de Engel, Rowthorn e Ramaswamy (1997) apontam, ainda, que, durante a industrialização, a elasticidade-renda da demanda por alimentos diminui e a elasticidade-renda por manufaturados aumenta, o que leva a economia a consumir mais manufaturados relativamente a alimentos. Ao longo do tempo, a consolidação da indústria e a elevação de sua produtividade reduzem os preços relativos dos manufaturados e suas elasticidades-renda, enquanto as elasticidades-renda por serviços aumentam. Com o crescimento da renda no tempo, a consequente maior demanda por serviços resulta em contratação de mais trabalhadores pelo setor, aumentando sua partici- 
pação na geração de empregos e reduzindo as participações dos demais setores, o que se configuraria como um processo de desindustrialização pela dimensão emprego, mas que pode não ter reflexo em termos da participação da indústria no Produto Interno Bruto (PIB).

Para justificar sua proposta, Tregenna (2009) utiliza o argumento de que processos kaldorianos operam especificamente via produção. Por exemplo, dois países que sofrem reduções equivalentes das participações industriais no emprego, com a participação no PIB diminuindo em apenas um deles, passam por desindustrializações pelo critério do emprego; porém, os impactos no crescimento são distintos. Pelos pressupostos de Kaldor (1966) de que a indústria tem propriedades importantes para o crescimento, como maiores efeitos de encadeamento para frente e para trás com os demais setores, economias de escala e efeitos de aprendizagem (learning-by-doing), variações da produção industrial proporcionam estímulos maiores do que variações no emprego. Assim, mesmo se o emprego cair, se a produção industrial crescer, a economia é beneficiada por demanda maior por insumos com encadeamentos para trás ou por reduções de custos para setores com encadeamentos para frente.

Ademais, a indústria pode elevar sua participação no PIB, mesmo com a queda da participação no emprego, se o crescimento da intensidade do trabalho industrial for menor do que o crescimento da intensidade do trabalho da economia. A intensidade do trabalho industrial altera-se por mudanças tecnológicas e/ou na composição das atividades industriais. Se a composição da indústria muda em direção a atividades menos intensivas em trabalho, sua intensidade do trabalho cai e o emprego cresce menos do que o produto industrial. Já mudanças tecnológicas podem resultar em menor número de empregados, mesmo com aumento no produto industrial, e queda na intensidade do trabalho maior do que na economia, levando ao declínio na participação no emprego. A convergência destes fatores justifica, para Tregenna (2009), a necessidade de definir e interpretar como desindustrialização um processo de declínio sustentado da participação da indústria tanto no emprego quanto no produto.

O conceito ampliado é defendido em diversos trabalhos. Oreiro e Feijó (2010), por exemplo, ressaltam que ele é compatível com diferentes variações da produção em termos físicos. Assim, uma economia não está se desindustrializando quando sua produção industrial diminui, mas sim quando sofre redução da importância da indústria como fonte de geração de emprego e de valor adicionado. Consequentemente, a expansão da escala da produção industrial também não pode ser interpretada como evidência de ausência de desindustrialização. Ademais, diminuição da participação da indústria pode não decorrer de reprimarização da pauta exportadora, mas sim do aumento da participação de produtos de maior conteúdo tecnológico ou de maior valor adicionado nas exportações, 
com efeitos benéficos sobre a economia. Nesse caso, a desindustrialização pode ser interpretada como positiva.

Aprofundando o debate, vale apontar que, em países com menores níveis de renda per capita, as participações dos setores primários nas gerações de emprego e de produto são elevadas. Porém, quando atingem certos níveis de renda, as participações industriais passam a predominar. Já em níveis maiores, os serviços predominam (NASSIF, 2008). Portanto, ocorrem alterações das participações relativas dos setores no emprego e no produto em função da dinâmica da renda (desenvolvimento ou crescimento econômico). Rowthorn e Ramaswamy (1997), considerando economias desenvolvidas e argumentos de Clark (1957), defendem que desindustrialização não é necessariamente indesejável, desde que seja um processo "natural" atrelado ao desenvolvimento e, consequentemente, ao aumento do padrão de vida e a diferenças de produtividade do trabalho entre os setores industrial e de serviços.

Palma (2005), por sua vez, defende que países desenvolvidos e industrializados alcançaram a fase de desindustrialização entre o final dos anos 1960 e o início dos anos 1970, ao passo que países de elevada renda, mas ainda em desenvolvimento, iniciaram tal processo na década de 1980. O grande problema é que, neste mesmo momento, outros países, em especial alguns latino-americanos, também começaram a se desindustrializar, mas com níveis de renda inferiores aos observados nos países que já haviam se desindustrializado ou estavam se desindustrializando. Nesse caso, o autor defende que o processo é "precoce", pois limita as possibilidades de desenvolvimento sustentado da economia.

Complementando esta discussão, Palma (2005) aponta, ainda, quatro fontes (hipóteses) para a desindustrialização, sendo as três primeiras relacionadas à hipótese de processo "natural". A primeira é a de existência de uma relação no formato de "U-invertido" entre a participação industrial e a renda per capita. Ou seja, à medida que a renda aumenta, a participação industrial se eleva, mas, atingido certo nível (turning point), esta participação diminui e é ultrapassada pela participação dos serviços. A segunda refere-se à relação inversa entre a importância industrial e a renda, em razão do contínuo declínio no tempo da participação industrial em países com rendas média e alta em decorrência de mudanças tecnológicas e realocação de parte dos processos de produção intensivos em mão de obra para outros países. A terceira refere-se ao declínio da renda de turning point da relação entre o grau de industrialização e a renda, sugerindo redução ao longo do tempo da relação em "U-invertido".

A quarta (menos importante para o presente estudo) é a da desindustrialização "induzida" por um problema de "doença holandesa", que faz com que a redução da participação industrial seja maior do que a esperada pelas três fontes anteriores. Nesse caso, a retração advém do avanço de atividades primárias com 
vantagens comparativas ricardianas, da descoberta de fontes de recursos naturais ou da abundância de recursos humanos "baratos". Para Palma (2005), tal fonte explica o caso da Holanda e de alguns países latino-americanos que perderam participação industrial acima do esperado para um processo "natural" principalmente devido à especialização em setores primários, que aumentaram a entrada de divisas por exportações, apreciando o câmbio e afetando a competitividade industrial.

Alguns países que desenvolveram exportações de serviços financeiros (Suíça, Luxemburgo e Hong Kong, por exemplo) ou de turismo (Grécia, Chipre e Malta, por exemplo) também vivenciaram uma desindustrialização prematura. Palma (2005) ressalta que, no caso dos países latino-americanos, a redução da participação industrial também estaria atrelada à adoção de políticas macroeconômicas, como a liberalização comercial e financeira, que resultaram em reversão do processo de substituição de importações para o padrão ricardiano rico em recursos naturais. Nesse caso, segundo Oreiro e Feijó (2010), a desindustrialização é negativa, pois restringe o potencial crescimento de longo prazo.

Para evidências referentes às três primeiras hipóteses apontadas por Palma (2005), podem ser destacados dois trabalhos mais recentes. O primeiro é o de Rodrik (2015), que avalia a possibilidade de desindustrialização precoce em países desenvolvidos e em desenvolvimento (América Latina, Ásia e África subsaariana) considerando a participação industrial no emprego e no produto, nominal e real. As evidências sugerem relações no formato de um "U-invertido": as participações da indústria no emprego e no produto aumentam em níveis baixos de renda per capita, mas passam diminuir a partir de certo estágio de desenvolvimento. Além disso, o turning point para a participação industrial no emprego é inferior ao do produto nominal, que, por sua vez, é inferior ao do produto real. Tais resultados são mais robustos nos países da América Latina e africanos. Países asiáticos e países com vantagens comparativas nas exportações de manufaturas parecem não lidar com tal problema. Nas economias avançadas, a desindustrialização é mais evidente pela medida do emprego, sobretudo nos setores que empregam mão de obra pouco qualificada, e decorre do progresso tecnológico (aumento da produtividade do trabalho) e de diferenças das elasticidades-renda entre produtos manufaturados e serviços. Já nas economias em desenvolvimento, a desindustrialização está atrelada ao comércio e à globalização, com tais países importando produtos industriais a preços relativos menores e, assim, revertendo o processo de substituição de importações que promovia o desenvolvimento industrial.

O segundo trabalho é o de Tregenna (2015), que, ao analisar 101 países agrupados pelos níveis de renda e por regiões no período de 1970 a 2010, encontra evidências de desindustrialização em todos. Segundo a autora, o início da desindustrialização ocorreu mais cedo (anos 1970) nos países de renda alta e mais tarde (entre 1990 e 2000) nos países de baixa renda. Os países em desenvolvimento 
perdem participação da indústria no produto e no emprego em níveis de industrialização menores do que os observados nos países avançados, indicando desindustrialização precoce (prematura). Nos países de renda baixa, em especial os da África subsaariana, o processo é de "desindustrialização pré-industrialização", ou seja, ocorre antes de uma real industrialização da economia. Além disso, os países em todos os grupos estão se desindustrializando com níveis de renda per capita e participações da indústria menores, o que impede o catch-up entre as economias. Todavia, há uma heterogeneidade no processo, em especial no que se refere aos efeitos negativos sobre o crescimento, que dependem da natureza das atividades industriais que estão em contração, isto é, se as atividades industriais em declínio forem ou não tecnologicamente mais avançadas e capazes de gerar retornos crescentes de escala e de produtividade cumulativos quando comparadas às atividades em expansão, os serviços.

\section{Evidências Empíricas: Dinâmica Regional da (des)/ndustrialização no Brasil}

O debate sobre a desindustrialização no âmbito agregado brasileiro é um tema recorrente na literatura econômica. Porém, as evidências empíricas não permitem corroborar, de forma irrefutável, a hipótese de que o país, em décadas recentes, vem passando ou passou por este processo. Além disso, os trabalhos que obtêm evidências positivas não são consensuais em relação às causas do problema, ou seja, se é um processo "natural" ou "induzido" por "doença holandesa" ou políticas econômicas. ${ }^{1}$

Por outro lado, discussões sobre possíveis desindustrializações nas esferas regionais brasileiras ainda são relativamente incipientes, principalmente em termos de evidências empíricas. Contudo, percebe-se que trabalhos mais recentes vêm demonstrando preocupação em avaliar se ocorre perda de importância relativa das atividades industriais em diferentes locais do Brasil. Alguns consideram, inclusive, as hipóteses inter-relacionadas do processo "natural" e do formato em "U-invertido".

Antes de discutir algumas evidências desses trabalhos, é importante apontar que, segundo Cano (1977, 1981), a industrialização brasileira apresentou desenvolvimento desigual até a década de 1970, concentrando as atividades industriais na região Sudeste, principalmente no estado de São Paulo. De acordo com vários estudos, a tendência concentradora passou a ser revertida, ao menos parcialmente, no período do "Milagre Econômico" e, em especial, depois do II Plano Nacional

1 Argumentos e evidências empíricas sobre este debate podem ser observados, por exemplo, em: Bonelli (2005), Feijó, Carvalho e Almeida (2005), Palma (2005), Nakahodo e Jank (2006), Bresser-Pereira (2007), Nassif (2008), Oreiro e Feijó (2010), Margarido, Serigati e Perosa (2011) e Nunes, Casonato e Costa (2014). 
de Desenvolvimento (PND), devido a políticas federais voltadas para as demais regiões. Recentemente, a desconcentração parcial se manteve, mas menos devido a políticas indutoras federais e mais em função de uma "guerra fiscal" entre governos subnacionais e de decisões das próprias empresas em busca de localidades com vantagens em termos de custos (infraestrutura, logística e insumos, por exemplo) e de mercados consumidores (CANO, 1997a, 1997b; AZEVEDO; TONETO JÚNIOR, 2001; SABOIA, 2001).

Cruz e Santos (2011) avaliam o emprego industrial nas microrregiões geográficas do país entre 1990 e 2009. Encontram evidências que sugerem a relação em "U-invertido" entre o peso da indústria e a renda per capita. Além disso, observam desconcentração industrial, com perda de importância das Regiões Metropolitanas (RMs) de São Paulo e do Rio de Janeiro e crescimento de microrregiões industriais (mais de 5 mil empregos) no Centro-Oeste e Sul, principalmente nos estados do Paraná e de Santa Catarina. Regiões com base industrial relevante, como o interior de São Paulo, ainda que tenham sofrido redução da participação industrial no emprego total, especializaram-se em indústrias de maior conteúdo tecnológico, com ganhos de empregos em setores capital-intensivo. Assim, nesse caso, a desindustrialização poderia ser considerada como positiva, conforme discutido anteriormente.

Botelho, Sousa e Avellar (2014) analisam informações sobre a atividade industrial e a inserção externa dos estados brasileiros no período de 1990 a 2010 e obtêm evidências de perda da participação da indústria no PIB na maioria dos estados, especialmente das regiões Sudeste e Nordeste. Em 14 estados, houve redução da participação industrial no emprego total, apesar de ocorrer crescimento do emprego e da produtividade industrial em todos os estados. Em 12 estados, ocorreu perda na razão entre o Valor da Transformação Industrial (VTI) e o Valor Bruto da Produção Industrial (VBPI), sinalizando menor agregação de valor à produção. A participação de manufaturados nas exportações diminuiu em 13 estados e, em 16, caiu a participação nas importações. Diante dessas evidências, as autoras defendem que a maior parte dos estados brasileiros pode ter passado por um processo de desindustrialização.

Monteiro e Lima (2014), com informações de 1985 a 2010, verificam que, nas regiões Sudeste, Nordeste e Sul, existem indícios mais fortes de desindustrialização, com perda da participação da indústria de transformação no valor adicionado (VA). Já em termos de participação da população ocupada na indústria de transformação, os dados também indicam desindustrialização no Sudeste e no Norte. Os autores constatam uma desconcentração das indústrias tradicionais do Sudeste para as demais regiões, mas pouca desconcentração regional das indústrias com maior conteúdo tecnológico. Ademais, regressões da participação da indústria de transformação no PIB em função da renda per capita sugerem que 
a redução da participação da indústria no Nordeste é precoce relativamente ao Sudeste e Sul, pois o perfil subsetorial da indústria nordestina é composto por indústrias tradicionais.

Spíndola e Lima (2015) usam dados regionais e estaduais de 1985 a 2010 para avaliar se ocorreu perda de participação da indústria de transformação no PIB e emprego nas regiões geográficas. No caso do VA, há indícios de desindustrialização no Nordeste, Sudeste e Sul. Em termos de emprego, de 2002 a 2012, Norte e Sudeste parecem ter sofrido desindustrialização, enquanto Nordeste, Centro-Oeste e Sul foram na direção oposta. Além disso, estimam um modelo paramétrico da participação da indústria de transformação regional no PIB em função da renda per capita da região. Os resultados corroboram a hipótese do "U-invertido" e revelam baixo nível de renda de turning point do Nordeste em comparação ao Sudeste e Sul, o que sugere que, na primeira região, o processo pode ser precoce.

Nunes, Casonato e Costa (2014) utilizam dados dos estados brasileiros de 2004 a 2010 para estimações em painel (efeitos fixos e aleatórios) para avaliar as relações entre a taxa de variação da proporção do emprego industrial na população economicamente ativa e as taxas de variação do PIB. Os resultados sinalizam que variação de $1 \%$ no PIB gera variação de $0,32 \%$ na participação do emprego industrial.

Alguns trabalhos analisam casos específicos. Por exemplo, Silva (2013) averigua a ocorrência de desindustrialização, de 1995 a 2010, no Rio Grande do Sul e em suas microrregiões. As evidências sugerem que a participação da indústria de transformação no VA total caiu, sendo tal queda absorvida pelo setor de serviços. As exportações agrícolas ganharam participação em detrimento da indústria, indicando reprimarização das exportações. A análise das microrregiões revela que 9 das 28 perderam parcela da indústria no VA total de 1999 a 2010, com expansão dos serviços e redução da renda per capita relativamente à média estadual, o que sugere desindustrialização "natural", mas negativa.

Barbosa, Carmo e Rahier (2015) avaliam a ocorrência de desindustrialização nas microrregiões no Paraná de 1996 a 2012, considerando as evoluções da participação do emprego industrial, do valor adicionado fiscal da indústria (VAFI) e da composição da pauta exportadora. Observa-se redução da participação industrial em algumas microrregiões, com especialização voltada às exportações de bens com pouco valor agregado. Ademais, estimações com dados em painel que relacionam a participação do emprego industrial e do VAFI ao PIB per capita não fornecem evidências robustas para corroborar a hipótese da relação entre a participação industrial e a renda per capita no formato de um "U-invertido".

Caçador (2015), por sua vez, averigua a ocorrência de desindustrialização no estado do Espírito Santo. Para isso, faz estimações por mínimos quadrados ordinários (MQO) para verificar se existe a relação em "U-invertido" entre a participação 
da indústria no valor adicionado e o valor adicionado total (VAT) per capita. Os resultados não sinalizam a ocorrência do formato. $\mathrm{O}$ autor atribui tal fato à estrutura industrial do estado ser fortemente concentrada em commodities, tanto que as estimações apontam que os preços delas afetam significativa e positivamente a participação industrial no VAT.

Outro conjunto de trabalhos investiga a ocorrência de desindustrialização com dados de regiões metropolitanas ou munícipios brasileiros. Fagundo (2008) avalia a ocorrência do processo na Região Metropolitana de São Paulo. As evidências indicam que o VAFI da região reduziu de 1980 a 1999, ao passo que o interior paulista passou a ganhar mais relevância. A população ocupada na indústria de transformação também caiu no período, com avanço do setor de serviços, embora este não tenha absorvido toda a mão de obra dispensada, o que sinaliza desindustrialização negativa. Porém, a autora alega que nos anos de 2000 a desindustrialização não teve continuidade, pois a participação industrial no VAF se manteve estável e a população ocupada na indústria de transformação reduziu pouco.

Silva (2010) considera as transformações na estrutura industrial em termos da participação no produto e no emprego na Região Metropolitana do Rio de Janeiro entre as décadas de 1990 e 2000. Verifica-se que a região se mantém como principal espaço econômico do estado, especialmente nas atividades terciárias e, em menor monta, na indústria. No entanto, entre 1997 e 2006, a participação da região no VAF do estado reduziu e a participação do interior aumentou, devido, em grande parte, à expansão das atividades petrolíferas. Além disso, as participações da indústria da cidade do Rio de Janeiro no VA e no emprego totais do estado caíram, sugerindo uma possível desindustrialização.

Saiani e Perosa (2014) avaliam a hipótese de desindustrialização "natural" por regressões não paramétricas com dados de 2010 dos municípios brasileiros. As evidências são favoráveis à hipótese, indicando tendência de aumento das participações industriais no VA e no emprego à medida que o PIB per capita municipal aumenta, com reversão da tendência em níveis mais elevados de PIB. Ademais, a indústria apresenta participações no VA e no emprego inferiores às da agropecuária e serviços até certo nível de renda, a partir do qual as ultrapassa, voltando a cair quando a renda atinge níveis mais elevados. Observa-se, ainda, que VA e emprego industriais aumentaram nos anos 2000 em termos absolutos e relativos no Norte, Centro-Oeste e Nordeste, regiões com menores rendas e setores industriais menos consolidados; já o Sul e o Sudeste perderam participação no VA e emprego.

Percebe-se, portanto, que a preocupação com o provável processo de desindustrialização no contexto regional brasileiro vem ganhando espaço no debate acadêmico. Porém, é preciso aprofundar estratégias empíricas robustas para o tratamento desse processo, principalmente para averiguar as hipóteses de desindustrialização "natural”, "U-invertido" e precoce (prematura). Os poucos traba- 
lhos existentes usam metodologias distintas (não paramétricas, MQO e dados em painel, por exemplo). O presente estudo contribui para a obtenção de evidências robustas por meio de dados municipais em painel e estratégias empíricas que permitem, inclusive, considerar disparidades entre as diferentes localidades do país. Antes de apresentar estas estratégias, são realizadas breves análises descritivas.

\section{Análises Descritivas: Dinâmica Regional da Indústria com Dados Munici- pais de 1999 e 2011}

As análises realizadas a seguir consideram informações municipais, referentes aos anos de 1999 e 2011, agregadas para as cinco regiões geográficas e para o Brasil. O período foi definido justamente pela disponibilidade dessas informações, oriundas do Instituto Brasileiro de Geografia e Estatística (IBGE). ${ }^{2}$ A Tabela 1 apresenta as evoluções dos empregos formais nos principais setores econômicos, em termos absolutos e relativos (participações no total). Observa-se que os empregos em todos os setores cresceram, em termos absolutos, no país como um todo e em todas as regiões. Na indústria, o emprego cresceu muito mais no Centro-Oeste, Norte e Nordeste em comparação ao Sul e Sudeste, sendo que as duas últimas regiões apresentam maiores níveis de renda e de consolidação da indústria.

Tabela 1 - Municípios brasileiros: evoluções dos somatórios dos empregos formais, segundo os principais setores econômicos, o Brasil e as grandes regiões geográficas (1999 a 2011)

\begin{tabular}{c|c|c|c|c|c|c}
\hline \multirow{2}{*}{ Indicador } & \multicolumn{3}{|c|}{ Milhões de Empregados } & \multicolumn{3}{c}{ \% do Emprego Total } \\
\cline { 2 - 7 } & $\mathbf{1 9 9 9}$ & $\mathbf{2 0 1 1}$ & $\mathbf{\Delta \% ( 9 9 - 1 1 )}$ & $\mathbf{1 9 9 9}$ & $\mathbf{2 0 1 1}$ & $\mathbf{\Delta \%}(\mathbf{9 9 - 1} \mathbf{1})$ \\
\hline \multicolumn{7}{c}{ Brasil } \\
\hline Emprego Total & 25,04 & 46,30 & 84,92 & 100,00 & 100,00 & 0,00 \\
Emprego Indústria & $\mathbf{4 , 6 0}$ & $\mathbf{8 , 1 1}$ & $\mathbf{7 6 , 2 4}$ & $\mathbf{1 8 , 3 9}$ & $\mathbf{1 7 , 5 3}$ & $\mathbf{- 4 , 6 9}$ \\
Emprego & 1,04 & 1,48 & 43,32 & 4,14 & 3,21 & $-22,50$ \\
Agropecuária & 7,99 & 15,37 & 92,49 & 31,90 & 33,20 & 4,09 \\
Emprego Serviços & \multicolumn{7}{c}{ Região Norte } \\
\hline Emprego Total & 1,03 & 2,56 & 148,30 & 100,00 & 100,00 & 0,00 \\
\hline Emprego Indústria & $\mathbf{0 , 1 3}$ & $\mathbf{0 , 2 9}$ & $\mathbf{1 2 6 , 4 7}$ & $\mathbf{1 2 , 3 9}$ & $\mathbf{1 1 , 3 0}$ & $\mathbf{- 8 , 7 9}$ \\
\hline
\end{tabular}

2 Como são consideradas agregações de dados municipais, podem ocorrer discrepâncias em relação a dados oficiais para níveis agregados (estados, regiões e Brasil). Acredita-se que, se existir, esse problema não prejudica os objetivos das análises, pois também são utilizados dados de fontes oficiais. Deve-se ressaltar, ainda, que as participações dos setores analisados não somam 100\% por não serem considerados todos os setores com dados discriminados e disponibilizados. 


\begin{tabular}{|c|c|c|c|c|c|c|}
\hline \multirow{2}{*}{ Indicador } & \multicolumn{3}{|c|}{ Milhões de Empregados } & \multicolumn{3}{|c|}{ \% do Emprego Total } \\
\hline & 1999 & 2011 & $\Delta \%(99-11)^{*}$ & 1999 & 2011 & $\Delta \%(99-11) *$ \\
\hline $\begin{array}{c}\text { Emprego } \\
\text { Agropecuária }\end{array}$ & 0,02 & 0,08 & 275,29 & 2,14 & 3,24 & 51,14 \\
\hline Emprego Serviços & 0,24 & 0,59 & 145,11 & 23,30 & 23,00 & $-1,29$ \\
\hline \multicolumn{7}{|c|}{ Região Nordeste } \\
\hline Emprego Total & 4,18 & 8,48 & 102,82 & 100,00 & 100,00 & 0,00 \\
\hline Emprego Indústria & 0,54 & 1,08 & 100,82 & 12,85 & 12,72 & $-0,99$ \\
\hline $\begin{array}{c}\text { Emprego } \\
\text { Agropecuária }\end{array}$ & 0,16 & 0,24 & 57,82 & 3,71 & 2,89 & $-22,19$ \\
\hline Emprego Serviços & 1,12 & 2,38 & 113,27 & 26,73 & 28,11 & 5,15 \\
\hline \multicolumn{7}{|c|}{ Região Centro-Oeste } \\
\hline Emprego Total & 1,91 & 3,85 & 101,12 & 100,00 & 100,00 & 0,00 \\
\hline Emprego Indústria & 0,18 & 0,45 & 148,16 & 9,37 & 11,56 & 23,39 \\
\hline $\begin{array}{c}\text { Emprego } \\
\text { Agropecuária }\end{array}$ & 0,12 & 0,25 & 112,60 & 6,17 & 6,53 & 5,71 \\
\hline Emprego Serviços & 0,58 & 1,14 & 95,97 & 30,46 & 29,68 & $-2,56$ \\
\hline \multicolumn{7}{|c|}{ Região Sudeste } \\
\hline Emprego Total & 13,50 & 23,50 & 74,07 & 100,00 & 100,00 & 0,00 \\
\hline Emprego Indústria & 2,60 & 4,24 & 62,99 & 19,27 & 18,04 & $-6,37$ \\
\hline $\begin{array}{c}\text { Emprego } \\
\text { Agropecuária }\end{array}$ & 0,55 & 0,68 & 23,40 & 4,06 & 2,88 & $-29,11$ \\
\hline Emprego Serviços & 4,79 & 8,88 & 85,28 & 35,49 & 37,77 & 6,44 \\
\hline \multicolumn{7}{|c|}{ Região Sul } \\
\hline Emprego Total & 4,41 & 7,90 & 79,28 & 100,00 & 100,00 & 0,00 \\
\hline Emprego Indústria & 1,16 & 2,06 & 77,92 & 26,27 & 26,07 & $-0,76$ \\
\hline $\begin{array}{c}\text { Emprego } \\
\text { Agropecuária }\end{array}$ & 0,19 & 0,23 & 19,07 & 4,36 & 2,89 & $-33,58$ \\
\hline Emprego Serviços & 1,25 & 2,38 & 89,80 & 28,44 & 30,11 & 5,87 \\
\hline
\end{tabular}

Fonte: Elaboração própria a partir de dados do Ministério do Trabalho e Emprego (BRASIL, 1999 a 2011).

Nota: * Variação percentual de 1999 a 2011.

Em termos relativos, o Centro-Oeste foi a única região na qual a participação da indústria no emprego formal total cresceu no período. Nas demais regiões e no país, as participações industriais caíram. Ademais, verifica-se que somente no Norte e no Centro-Oeste a participação da agropecuária aumentou no período. Ou seja, estas são as únicas regiões que, pela análise da dimensão emprego, apresen- 
tam evidências de possível reprimarização que pode derivar de desindustrialização "induzida" - considerando a agropecuária como uma proxy, mas reconhecendo que tal opção é sujeita a diversas críticas. Contribui para o argumento a queda da participação dos serviços apenas nestas regiões. Vale ressalvar que a expansão da participação da indústria no Centro-Oeste foi superior à da agropecuária. No país e nas demais regiões com reduções das participações da indústria e da agropecuária, as quedas foram maiores no último setor. Ademais, as participações dos serviços se elevaram. Essas evidências são favoráveis à hipótese de desindustrialização "natural" e à desconcentração regional da indústria.

A Tabela 2, por sua vez, mostra as evoluções dos PIBs e dos VAs setoriais, em termos absolutos e relativos (participações no PIB). Verifica-se, primeiramente, que os somatórios dos PIBs municipais e dos VAs no Brasil e em todas as regiões aumentaram de 1999 a 2011 . Nordeste e, principalmente, Norte e Centro-Oeste foram as regiões com maiores aumentos do VA industrial. Ou seja, em termos absolutos, regiões com menores rendas e com setores industriais menos consolidados foram as que apresentaram maiores aumentos dos VAs da indústria. Em termos relativos, Norte e Centro-Oeste também apresentaram elevações das participações da indústria no PIB. O mesmo ocorreu no Sudeste, mas em magnitude bastante inferior. Esses aumentos compensaram as quedas das participações nas demais regiões, de modo que no país a participação do VA industrial no PIB praticamente não alterou. No Nordeste e Sul, as participações dos VAs de todos os setores analisados reduziram no período.

Tabela 2 - Municípios brasileiros: evoluções dos somatórios dos PIBs e dos valores adicionados (VAs) dos principais setores econômicos, segundo o Brasil e as grandes regiões geográficas (1999 a 2011)

\begin{tabular}{c|c|c|c|c|c|c}
\hline \multirow{2}{*}{ Indicador } & \multicolumn{3}{|c|}{ R\$ Bilhões de 2000 } & \multicolumn{3}{c}{ \% do PIB } \\
\cline { 2 - 7 } & $\mathbf{1 9 9 9}$ & $\mathbf{2 0 1 1}$ & $\mathbf{\Delta \% ~ ( 9 9 - 1 ~ 1 ) *}$ & $\mathbf{1 9 9 9}$ & $\mathbf{2 0 1 1}$ & $\mathbf{\Delta \%}(\mathbf{9 9 - 1 1})$ \\
\hline PIB & $1.130,79$ & $1.824,23$ & 61,32 & 100,00 & 100,00 & 0,00 \\
VA Indústria & $\mathbf{2 5 5 , 6 1}$ & $\mathbf{4 2 1 , 6 4}$ & $\mathbf{6 4 , 9 6}$ & $\mathbf{2 2 , 6 0}$ & $\mathbf{2 3 , 1 1}$ & $\mathbf{2 , 2 5}$ \\
VA Agropecuária & 53,92 & 79,26 & 46,99 & 4,77 & 4,34 & $-8,88$ \\
VA Serviços & 675,63 & 800,30 & 18,45 & 59,75 & 43,87 & $-26,57$ \\
\hline \multicolumn{7}{c}{ Região Norte } \\
\hline PIB & 47,16 & 100,56 & 113,22 & 100,00 & 100,00 & 0,00 \\
VA Indústria & $\mathbf{1 0 , 2 2}$ & $\mathbf{2 9 , 7 8}$ & $\mathbf{1 9 1 , 3 5}$ & $\mathbf{2 1 , 6 7}$ & $\mathbf{2 9 , 6 1}$ & $\mathbf{3 6 , 6 4}$ \\
VA Agropecuária & 4,73 & 7,99 & 69,03 & 10,02 & 7,95 & $-20,72$ \\
VA Serviços & 27,77 & 31,31 & 12,77 & 58,87 & 31,14 & $-47,11$ \\
\hline
\end{tabular}


conclusão.

\begin{tabular}{|c|c|c|c|c|c|c|}
\hline \multirow{2}{*}{ Indicador } & \multicolumn{3}{|c|}{ R\$ Bilhões de 2000} & \multicolumn{3}{|c|}{$\%$ do PIB } \\
\hline & 1999 & 2011 & $\Delta \%(99-11) *$ & 1999 & 2011 & $\Delta \%(99-11) *$ \\
\hline \multicolumn{7}{|c|}{ Região Nordeste } \\
\hline PIB & 140,77 & 243,34 & 72,87 & 100,00 & 100,00 & 0,00 \\
\hline VA Indústria & 29,51 & 47,11 & 59,63 & 20,96 & 19,36 & $-7,66$ \\
\hline VA Agropecuária & 9,34 & 14,91 & 59,58 & 6,64 & 6,13 & $-7,69$ \\
\hline VA Serviços & 86,75 & 99,24 & 14,40 & 61,62 & 40,78 & $-33,82$ \\
\hline \multicolumn{7}{|c|}{ Região Centro-Oeste } \\
\hline PIB & 99,11 & 166,84 & 68,33 & 100,00 & 100,00 & 0,00 \\
\hline VA Indústria & 10,74 & 24,88 & 131,72 & 10,83 & 14,91 & 37,66 \\
\hline VA Agropecuária & 7,33 & 14,29 & 95,02 & 7,39 & 8,57 & 15,85 \\
\hline VA Serviços & 71,92 & 65,68 & $-8,67$ & 72,56 & 39,37 & $-45,74$ \\
\hline \multicolumn{7}{|c|}{ Região Sudeste } \\
\hline PIB & 658,41 & $1.023,20$ & 55,40 & 100,00 & 100,00 & 0,00 \\
\hline VA Indústria & 158,05 & 247,71 & 56,73 & 24,00 & 24,21 & 0,85 \\
\hline VA Agropecuária & 17,79 & 21,82 & 22,59 & 2,70 & 2,13 & $-21,11$ \\
\hline VA Serviços & 386,42 & 481,79 & 24,68 & 58,69 & 47,09 & $-19,77$ \\
\hline \multicolumn{7}{|c|}{ Região Sul } \\
\hline PIB & 185,34 & 290,29 & 56,63 & 100,00 & 100,00 & 0,00 \\
\hline VA Indústria & 47,09 & 72,17 & 53,25 & 25,41 & 24,86 & $-2,16$ \\
\hline VA Agropecuária & 14,73 & 20,25 & 37,53 & 7,95 & 6,98 & $-12,19$ \\
\hline VA Serviços & 102,78 & 122,28 & 18,97 & 55,45 & 42,12 & $-24,04$ \\
\hline
\end{tabular}

Fonte: Elaboração própria a partir de dados do IBGE (1999 a 2011).

Nota: * Variação percentual de 1999 a 2011.

As evoluções dos VAs setoriais municipais agregados sinalizam, portanto, que o Brasil pode não ter sofrido desindustrialização de 1999 a 2011, pois a participação do VA industrial no PIB sofreu um pequeno aumento. Mesmo considerando a redução da participação industrial no emprego (Tabela 1), a desindustrialização pode ser refutada, pois, como já foi discutido, queda do emprego industrial também pode refletir outros aspectos, como ganhos de produtividade e expansão de setores industriais com maiores conteúdos tecnológicos. As variações das participações da agropecuária (diminuição no emprego e no PIB) e dos serviços (elevação no emprego e redução no PIB) não possibilitam inferir, mesmo se for assumida uma desindustrialização, baseando-se no emprego e em indícios de outros trabalhos - contestados por outros -, se esta é decorrente de um processo "induzido" ou "natural". 
Pelas análises por regiões, mesmo naquelas com indícios de uma possível desindustrialização, não é possível refutar a hipótese de que este processo é "natural", ou seja, atrelado à dinâmica do desenvolvimento econômico (renda per capita). Para aprofundar essa discussão, com evidências mais robustas, a seguir são feitas estimações econométricas com dados municipais anuais em painel. Antes de discutir as estratégias de estimação e os resultados, vale ressaltar que as breves análises descritivas realizadas nessa seção mostram evidências que corroboram ou refutam indícios de outros trabalhos, alguns revisados anteriormente. Isso denota a complexidade do tema, que depende de avaliações suscetíveis de influência dos indicadores, dados, níveis de agregação e períodos considerados. Por fim, vale destacar que as evidências dessa seção também sinalizam a permanência, na década de 2000, de outra tendência já comentada: a da desconcentração regional da indústria. No período, destacam-se, nesse sentido, as expansões dos empregos e dos VAs industriais no Norte e no Centro-Oeste.

\section{Estratégias Empíricas}

Para testar a hipótese da relação entre grau de industrialização e renda per capita no formato de um "U-invertido" para os municípios brasileiros, são realizadas estimações econométricas com dados municipais anuais em painel referentes ao período de 1999 a 2011 . As estimações são feitas para o Brasil e para cada uma de suas regiões geográficas (Sudeste, Norte, Nordeste, Centro-Oeste e Sul).

Vale apontar que o emprego de dados em painel é importante pela relação testada decorrer de processos dinâmicos de transformações na economia e por reduzir possíveis vieses de características omitidas específicas de cada município. O método de efeitos fixos (estimador Within e erros padrões robustos) é o utilizado, pois lida com viés de correlação entre as variáveis omitidas fixas no tempo e os regressores. Além disso, ao incorporar dummies anuais, são controlados efeitos comuns entre os municípios variantes no tempo - método Least Squares Dummy Variable Model with time Specific Effect (LSDV). O teste de Hausman é realizado para avaliar a adequação do método de efeitos fixos em comparação ao método de efeitos aleatórios. ${ }^{3}$ Os modelos estimados baseiam-se na equação (1).

$$
\mathrm{I}_{\mathrm{it}}=\beta_{0}+\beta_{1} \mathrm{Y}_{\mathrm{it}}+\beta_{2} \mathrm{Y}_{\mathrm{it}}{ }_{\mathrm{it}}+\beta_{3} \mathrm{X}_{\mathrm{it}}+\mathrm{T}_{\mathrm{t}}+\mu_{\mathrm{i}}+\varepsilon_{\mathrm{it}}
$$

3 Para mais detalhes sobre os aspectos metodológicos apontados, conferir, entre outros: Greene (1997), Baltagi (2001), Wooldridge (2002) e Cameron e Trivedi (2009). Resumidamente, o método de efeitos aleatórios, com estimação por mínimos quadrados generalizados (MQG), é o mais adequado se características não observadas não forem correlacionadas aos regressores. Já o de efeitos fixos, com estimação por mínimos quadrados ordinários (MQO), é o mais adequado se as características não observadas forem correlacionadas aos regressores. 
sendo: $I_{i t}$ as variáveis dependentes referentes ao município $i$ no ano $t$ $(t=1999, \ldots, 2011) ; \beta_{0}$ a constante; $Y_{i t}$ a variável explicativa de interesse; $\beta_{1}$ e $\beta_{2}$ os coeficientes associados à variável de interesse; $\mathrm{X}_{\mathrm{it}}$ um vetor de covariadas; $\beta_{3} \mathrm{o}$ vetor de coeficientes associados a estas; $\mathrm{T}_{\mathrm{t}} \mathrm{um}$ vetor de dummies anuais (1999 como default); $\mu_{\mathrm{i}}$ os efeitos fixos e $\varepsilon_{\mathrm{it}}$ o termo errático.

As variáveis dependentes $\left(\mathrm{I}_{\mathrm{i}}\right)$ representam duas proxies que são tradicionalmente utilizadas na literatura para sinalizar o grau de industrialização de uma economia e para identificar se esta sofre processo de desindustrialização, de acordo com o conceito ampliado de Tregenna (2009) discutido na segunda seção. A primeira proxy, chamada de Emprego Indústria, corresponde à proporção (\%) do emprego industrial no emprego formal total do município i no ano t. Para seu cálculo, são usados dados de vínculos formais da Relação Anual de Informações (RAIS) do Ministério do Trabalho e Emprego (MTE). A segunda proxy, denominada como VA Indústria, corresponde à proporção (\%) do VA da indústria no Produto Interno Bruto (PIB) do município i no ano $t$. As informações dos VAs industriais e dos PIBs são disponibilizadas pelo Instituto Brasileiro de Geografia e Estatística (IBGE).

O termo $\mathrm{Y}_{\mathrm{it}}$ representa a variável explicativa de interesse do presente estudo: o PIB per capita municipal (R\$1000 de 2000). Esta é a proxy para a renda per capita geralmente utilizada em trabalhos que testam a hipótese do "U-invertido". Como tal hipótese pressupõe uma relação não linear entre o grau de industrialização e a renda, o PIB per capita é considerado em um polinômio de $2^{\circ}$ grau. Para corroborar a hipótese, o coeficiente associado a tal variável em nível deve ser positivo e significativo $\left(\beta_{1}>0\right)$ e o coeficiente da variável ao quadrado deve ser negativo e significativo $\left(\beta_{2}<0\right)$. Se isso for observado, é uma evidência que sinaliza um aumento da participação industrial à medida que a renda municipal se eleva, mas, atingido certo nível, a participação diminui. Ou seja, a relação entre industrialização e renda per capita nos municípios tem um ponto de máximo (turning point). $\mathrm{O}$ PIB per capita municipal médio $(\bar{Y})$ nesse ponto é calculado derivando a equação (1) com os coeficientes estimados, em relação ao PIB per capita e resolvendo a condição de $1^{\text {a }}$ ordem, conforme (2) e (3).

$$
\begin{gathered}
\frac{\partial I_{i t}}{\partial Y_{i t}}=\beta_{1}+2 \beta_{2} Y_{i t}=0 \\
\bar{Y}=-\frac{\beta_{1}}{2 \beta_{2}}
\end{gathered}
$$

Os cálculos dos PIBs per capita médios de pontos máximos, os turning points, caso existam, permitem a verificação de duas hipóteses adicionais levantadas pela literatura e fundamentadas pela discussão brevemente revisada na segunda seção. A primeira é a de que, devido à produtividade do trabalho tender a aumentar mais 
rapidamente na indústria do que em outros setores, a participação industrial no emprego diminuiria "antes" do que a participação no PIB, ou seja, em um nível de renda menor (ROWTHORN; RAMASWAMY, 1997; TREGENNA, 2009; RODRIK, 2015). Evidência favorável à hipótese é obtida se o PIB per capita médio de ponto de máximo para a variável Emprego Indústria for menor do que o PIB per capitamédio de ponto de máximo para a variável VA Indústria.

A segunda hipótese é a de desindustrialização "precoce" ("prematura"), que pressupõe retração da participação da indústria em níveis de desenvolvimento (renda) inferiores aos de economias mais desenvolvidas (PALMA, 2005; OREIRO; FEIJÓ, 2010). Na ausência de um parâmetro consensual na literatura econômica do que seria um nível de renda per capita "ideal" para a desindustrialização não ser precoce, os PIBs per capita médios de pontos máximos das variáveis dependentes do Norte, Nordeste, Centro-Oeste, Sul e Brasil, se existirem, são comparados aos do Sudeste, que é a região com maiores PIB per capita médio e participações médias da indústria no produto e no emprego. Assim, são encontrados indícios de que os municípios das demais regiões e do Brasil apresentam, na média, uma desindustrialização precoce se seus turning points forem inferiores aos do Sudeste. Ou seja, a atribuição de precocidade é apenas uma comparação com a principal região industrial do país.

$\mathrm{Na}$ equação (1), o termo representa o vetor das características municipais variantes no tempo (covariadas) apresentadas no Quadro 1. Não existem muitos dados municipais disponíveis para todos os anos considerados neste estudo. Assim, as covariadas são as proxies disponíveis para controlar o tamanho do mercado consumidor (População); a disponibilidade e a qualificação da mão de obra (Formalização e Fundamental); a probabilidade de uma pessoa ficar doente (Morbidade), o que influencia sua produtividade no trabalho; as despesas públicas para estimular atividades econômicas (Bens Econômicos); o custo de vida e tributário (IPTU). Na survey da literatura de Ramos (2000), esses aspectos são apontados como determinantes da localização industrial. Assim, é plausível supor que também podem afetar a participação da indústria em um município. Ademais, como já apontado, benefícios fiscais, mercados consumidores e vantagens de custos influenciam a desconcentração da indústria no Brasil (CANO, 1997a, 1997b; AZEVEDO; TONETO JÚNIOR, 2001; SABOIA, 2001). Outros possíveis determinantes da localização industrial apontados por Ramos (2000) não variam no tempo, como localização geográfica e relevo, sendo captados pelos efeitos fixos 0 . As covariadas e os efeitos fixos controlam, então, disparidades locacionais que podem afetar a industrialização. 
Quadro 1 - Descrições das covariadas

\begin{tabular}{|c|c|c|}
\hline Variável & Descriçãa & Fonte \\
\hline População & $\begin{array}{c}\text { População residente total (milhares de } \\
\text { habitantes) }\end{array}$ & IBGE \\
\hline Formalização & $\begin{array}{l}\text { Empregos formais / população economi- } \\
\text { camente ativa (\%) }\end{array}$ & $\mathrm{MTE}^{(\mathrm{a})}$ e IBGE \\
\hline Fundamental & $\begin{array}{l}\text { Empregos com ensino fundamental ou } \\
\text { mais / empregos (\%) }\end{array}$ & $\mathrm{MTE}^{(a)}$ \\
\hline Morbidade & $\begin{array}{l}\text { Internações na rede pública de saúde (por } \\
\qquad 100 \text { habitantes) }\end{array}$ & $\mathrm{MS}^{(\mathrm{b})}$ \\
\hline Bens Econômicos & $\begin{array}{l}\text { Gasto com serviços econômicos }{ }^{(c)} \text { per } \\
\text { capita (R\$1000 de 2000) }\end{array}$ & $\mathrm{STN}^{(\mathrm{d})}$ \\
\hline IPTU & $\begin{array}{l}\text { Arrecadação com IPTU(e) per capita (R\$ } \\
1000 \text { de 2000) }\end{array}$ & $\mathrm{MTE}^{(\mathrm{a})}$ \\
\hline VA Agropecuária & VA da agropecuária / PIB (\%) & IBGE \\
\hline Emprego Agropecuária & $\begin{array}{c}\text { Empregos na agropecuária / empregos } \\
\text { formais (\%) }\end{array}$ & IBGE \\
\hline
\end{tabular}

Fonte: Elaboração própria.

Nota: (a) Ministério do Trabalho e Emprego. ${ }^{(b)}$ Ministério da Saúde. (c) Somatório dos gastos com agricultura, indústria, comércio, transporte, desenvolvimento regional, energia, recursos minerais e comunicações - classificação de Oxley e Martin (1991). (d) Secretaria do Tesouro Nacional. ${ }^{(e)}$ Imposto Predial e Territorial Urbano - principal tributo municipal.

Outro aspecto apontado anteriormente é que a relação entre a participação da indústria e a renda per capita no formato de um "U-invertido" decorre da dinâmica relativa dos setores industriais e de serviços. Para que os resultados reflitam esse aspecto, não sendo influenciados pela dinâmica de outro setor econômico de grande relevância, é controlada a participação da agropecuária no PIB (VA Agropecuária) ou no emprego (Emprego Agropecuária), dependendo de qual é a variável dependente em análise. No caso de o município sofrer os impactos de uma desindustrialização "induzida", uma consequência negativa é a reprimarização da economia, o que tende a aumentar a importância relativa da agropecuária. Assim, as variáveis referentes ao setor também podem captar esse possível efeito.

Conforme foi mencionado na primeira seção deste trabalho, condições macroeconômicas (taxas de câmbio e de juros e aberturas comercial e financeira, por exemplo) podem afetar a industrialização de um país (CANO, 2012). No presente estudo, são analisados municípios, de modo que fatores macroeconômicos e institucionais podem se alterar ao longo do tempo, porém é plausível supor que seus efeitos não diferem entre os municípios. Assim, são controlados pelas dummies anuais $\left(\mathrm{T}_{\mathrm{t}}\right)$.

Uma crítica que as estimações podem sofrer se refere ao fato das variáveis dependentes serem proporções (\%), de modo que variam entre 0 e 100. Ou seja, 
são censuradas em limites inferior e superior. Na presença de censura, as estimações por $\mathrm{MQO}$, como no método de painel com efeitos fixos, podem ser viesadas e inconsistentes. Uma opção é usar o método Tobit em painel, no qual a estimação é feita por máxima verossimilhança. Tal método é vantajoso por utilizar distribuição mais adequada para dados censurados. Porém, não é possível controlar efeitos fixos, ou seja, a estimação é feita considerando efeitos aleatórios. Além disso, os coeficientes não representam efeitos marginais ou médios, pois dependem da variável em análise e também das demais variáveis explicativas. Assim, o cálculo de turning points não é trivial, mas os sinais dos coeficientes podem ser interpretados. ${ }^{4}$

Portanto, para testar a robustez dos resultados, são realizadas estimações de modelos baseados na equação (2), desconsiderando o termo $\mu_{\mathrm{i}}$ (efeitos fixos), pelo método Tobit em painel. Para tais estimações, devido às especificidades do método, não são calculados os turning points, mas é possível inferir se é uma relação não linear em "U-invertido" pelos sinais e significâncias dos coeficientes. Assim como por efeitos fixos, o formato é corroborado se o coeficiente do PIB per capita em nível for positivo e significativo $\left(\beta_{1}>0\right)$ e o coeficiente deste ao quadrado for negativo e significativo $\left(\beta_{2}<0\right)$.

Por último, são realizadas estimações adicionais de modelos baseados na equação (1) com as variáveis dependentes representando a razão entre os empregos dos serviços e da indústria e a razão entre os VAs dos serviços e da indústria. Tais variáveis são chamadas de Emprego Serviços/Indústria e VA Serviços/Indústria, respectivamente. A hipótese de desindustrialização "natural" pressupõe que, ao longo do desenvolvimento, a participação industrial aumenta até certo estágio, a partir do qual a importância dos serviços se eleva em detrimento à da indústria (ROWTHORN; RAMASWAMY, 1997; NASSIF, 2008). As novas variáveis dependentes são utilizadas para testar essa hipótese.

Para que a hipótese seja corroborada, as relações entre as razões e o PIB per capita devem assumir o formato de um "U". Ou seja, até certo nível de renda per capita, a importância dos serviços relativamente à indústria diminui, mas, após esse turning point (ponto de mínimo), a importância relativa dos serviços aumenta. As estimações sinalizam evidências que não refutam a hipótese se o coeficiente do PIB per capita em nível for significativo e negativo $\left(\beta_{1}<0\right)$ e o coeficiente deste ao quadrado for significativo e positivo $\left(\beta_{2}>0\right)$. Nesse caso, não há censura. Assim, as estimações são feitas por efeitos fixos, sendo avaliada sua adequação em comparação ao método de efeitos aleatórios pelo teste de Hausman. Esta proposta de teste da hipótese do processo "natural" não foi encontrada em nenhum outro trabalho avaliado. Assim, configura-se como uma contribuição do presente estudo.

4 Conferir, por exemplo: Greene (1997), Baltagi (2001), Wooldridge (2002) e Cameron e Trivedi (2009). 


\section{Resultados}

A seguir, são analisados os resultados das estimações discutidas na seção anterior. Para não fugir do escopo deste estudo, são reportados somente os coeficientes estimados associados à variável PIB per capita em nível e ao quadrado. Os coeficientes estimados associados às covariadas constam em tabelas no Apêndice. ${ }^{5}$ Deve-se destacar que, nas estimações realizadas por efeitos fixos, os testes de Hausman sinalizam a melhor adequação deste método comparativamente ao de efeitos aleatórios, o que é sinalizado pelas estatísticas significativas dos testes, apresentadas nas tabelas de resultados.

A Tabela 3 apresenta os resultados obtidos nas estimações por efeitos fixos nas quais a variável dependente é o Emprego Indústria. Observa-se que, tanto no Brasil como nas regiões geográficas, os coeficientes estimados associados à variável PIB per capita em nível são positivos. Na região Norte, é significativo apenas a 10\%, mas no país como todo e nas demais regiões a significância é a 1\%. Já os coeficientes estimados associados ao PIB per capita ao quadrado são negativos e significativos - a 1\% no Brasil, Sudeste e Sul; a 5\% no Nordeste; e a 1\% no Norte e Centro-Oeste. Esses resultados não refutam a hipótese da relação entre industrialização e renda no formato de um "U-invertido".

5 Já os coeficientes estimados associados às dummies anuais e às constantes podem ser obtidos junto aos autores. 
Tabela 3 - Variável dependente Emprego Indústria:

estimações em painel com efeitos fixos

\begin{tabular}{|c|c|c|c|c|c|c|}
\hline $\begin{array}{l}\text { Variável/ } \\
\text { Região }\end{array}$ & Brasil & Sudeste & Norte & Nordeste & $\begin{array}{c}\text { Centro- } \\
\text { Oeste }\end{array}$ & Sul \\
\hline \multirow{2}{*}{ PIB per capita } & $0,129 * * *$ & $0,072 * * *$ & $0,267^{*}$ & $0,151 * *$ & $0,247^{* * *}$ & $0,333 * * *$ \\
\hline & $(0,015)$ & $(0,017)$ & $(0,152)$ & $(0,053)$ & $(0,083)$ & $(0,040)$ \\
\hline \multirow{2}{*}{ PIB per capita ${ }^{2}$} & $-0,001 * * *$ & $-0,001 * * *$ & $-0,004 *$ & $-0,001 * *$ & $-0,002 *$ & $-0,003 * * *$ \\
\hline & $(0,000)$ & $(0,000)$ & $(0,001)$ & $(0,000)$ & $(0,001)$ & $(0,001)$ \\
\hline Controles & Sim & Sim & Sim & Sim & Sim & Sim \\
\hline $\begin{array}{c}\text { Dummies } \\
\text { Anuais }\end{array}$ & Sim & Sim & Sim & Sim & Sim & Sim \\
\hline Constantes & Sim & Sim & Sim & Sim & Sim & Sim \\
\hline Prob $>F$ & 0,000 & 0,000 & 0,000 & 0,000 & 0,000 & 0,000 \\
\hline $\begin{array}{c}\text { Teste de } \\
\text { Hausman }\end{array}$ & $162,32^{* * *}$ & $364,12^{* * *}$ & $53,23 * * *$ & $231,00 * * *$ & $47,18 * * *$ & $280,78^{* * * *}$ \\
\hline Observações & 57.799 & 16.629 & 4.316 & 18.544 & 5.331 & 12.979 \\
\hline
\end{tabular}

Fonte: Elaboração própria.

Nota: Erros-padrão robustos entre parênteses. *** Significativo a 1\%. ** Significativo a 5\%.

* Significativo a $10 \%$.

Como já mencionado, em função dos dados das variáveis dependentes serem censurados entre 0 e 100, são feitas estimações adicionais pelo método Tobit em painel para garantir maior robustez às evidências. Os resultados das estimações por Tobit em painel para a variável dependente Emprego Indústria são apresentados na Tabela 4. Estes também corroboram a hipótese do "U-invertido" para o Brasil como um todo e para as suas grandes regiões geográficas: os coeficientes associados ao PIB per capita em nível são positivos e significativos (a 1\%) e os coeficientes associados à variável ao quadrado são negativos e significativos (a $1 \%)$. Portanto, pode-se inferir com certa robustez que, no país e nas suas regiões, a participação relativa da indústria no emprego formal municipal aumenta, na média, à medida que o PIB per capita dos municípios se eleva, mas passa a cair a partir de certo nível de renda. Assim, os resultados das Tabelas 3 e 4 sugerem que a evolução da participação industrial no emprego nos municípios brasileiros tende a ser influenciada pela dinâmica do desenvolvimento. 
Tabela 4 - Variável dependente Emprego Indústria:

estimações por Tobit em painel

\begin{tabular}{|c|c|c|c|c|c|c|}
\hline $\begin{array}{c}\text { Variável/ } \\
\text { Região }\end{array}$ & Brasil & Sudeste & Norte & Nordeste & $\begin{array}{c}\text { Centro- } \\
\text { Oeste }\end{array}$ & Sul \\
\hline PIB per capita & $\begin{array}{c}0,239 * * * \\
(0,016)\end{array}$ & $\begin{array}{c}0,119 * * * \\
(0,017)\end{array}$ & $\begin{array}{c}0,630 * * * \\
(0,180)\end{array}$ & $\begin{array}{c}0,342 * * * \\
(0,064)\end{array}$ & $\begin{array}{c}0,429 * * * \\
(0,081)\end{array}$ & $\begin{array}{c}0,403 * * * \\
(0,040)\end{array}$ \\
\hline PIB per capita & $\begin{array}{c}-0,001 * * * \\
(0,000)\end{array}$ & $\begin{array}{c}-0,001^{* * *} \\
(0,000)\end{array}$ & $\begin{array}{c}-0,011^{* * *} \\
(0,004)\end{array}$ & $\begin{array}{c}-0,002 * * * \\
(0,000)\end{array}$ & $\begin{array}{c}-0,004^{* * *} \\
(0,001)\end{array}$ & $\begin{array}{c}-0,003^{* * *} \\
(0,001)\end{array}$ \\
\hline Controles & Sim & Sim & Sim & Sim & Sim & Sim \\
\hline $\begin{array}{c}\text { Dummies } \\
\text { Anuais }\end{array}$ & Sim & Sim & Sim & Sim & Sim & Sim \\
\hline Constantes & Sim & Sim & Sim & Sim & Sim & Sim \\
\hline Prob $>$ chi $^{2}$ & 0,000 & 0,000 & 0,000 & 0,000 & 0,000 & 0,000 \\
\hline Observações & 57.799 & 16.629 & 4.316 & 18.544 & 5.331 & 12.979 \\
\hline
\end{tabular}

Fonte: Elaboração própria.

Nota: Erros-padrão robustos entre parênteses. * "* Significativo a 1\%. "* Significativo a 5\%.

* Significativo a 10\%.

Como foi discutido na segunda seção, é questionável a constatação de uma desindustrialização avaliando apenas a evolução da participação da indústria na geração de emprego. A recomendação da literatura é que também seja averiguada a participação da indústria no produto. No presente estudo, isso é realizado por meio da variável VA Indústria, que corresponde à participação do VA da indústria no PIB municipal. Os resultados das estimações por efeitos fixos em que esta é a variável dependente são apresentados na Tabela 5; já os resultados por Tobit em painel são apresentados na Tabela 6.

Na Tabela 5, observa-se que os coeficientes estimados associados ao PIB per capita em nível são positivos e significativos (a 1\%) no Brasil e em todas as suas regiões. Já os coeficientes associados ao PIB per capita ao quadrado são negativos e significativos (a 1\%) também em todas as regiões e no país como um todo. Portanto, no caso do VA industrial, os resultados também sugerem a existência de relações entre os graus de industrialização e as rendas per capita no formato de um "U-invertido". 
Tabela 5 - Variável dependente VA Indústria:

estimações em painel com efeitos fixos

\begin{tabular}{|c|c|c|c|c|c|c|}
\hline $\begin{array}{l}\text { Variável/ } \\
\text { Região }\end{array}$ & Brasil & Sudeste & Norte & Nordeste & $\begin{array}{c}\text { Centro- } \\
\text { Oeste }\end{array}$ & Sul \\
\hline PIB per capita & $\begin{array}{c}1,122 * * * \\
(0,011)\end{array}$ & $\begin{array}{c}0,802 * * * \\
(0,016)\end{array}$ & $\begin{array}{c}4,310 * * * \\
(0,085)\end{array}$ & $\begin{array}{c}1,926 * * * \\
(0,034)\end{array}$ & $\begin{array}{c}1,249 * * * \\
(0,046)\end{array}$ & $\begin{array}{c}1,625 * * * \\
(0,027)\end{array}$ \\
\hline PIB per capita ${ }^{2}$ & $\begin{array}{c}-0,005^{* * *} \\
(0,000)\end{array}$ & $\begin{array}{c}-0,003^{* * *} \\
(0,000)\end{array}$ & $\begin{array}{c}-0,064^{* * *} \\
(0,002)\end{array}$ & $\begin{array}{c}-0,009 * * * \\
(0,000)\end{array}$ & $\begin{array}{c}-0,009^{* * *} \\
(0,001)\end{array}$ & $\begin{array}{c}-0,009 * * * \\
(0,000)\end{array}$ \\
\hline Controles & Sim & Sim & Sim & Sim & Sim & Sim \\
\hline $\begin{array}{c}\text { Dummies } \\
\text { Anuais }\end{array}$ & Sim & Sim & Sim & Sim & Sim & Sim \\
\hline Constantes & Sim & $\operatorname{Sim}$ & Sim & Sim & Sim & Sim \\
\hline Prob $>F$ & 0,000 & 0,000 & 0,000 & 0,000 & 0,000 & 0,000 \\
\hline $\begin{array}{l}\text { Teste de } \\
\text { Hausman }\end{array}$ & $351,15^{* * *}$ & $253,63 * * *$ & $189,26 *$ & $375,22^{* * *}$ & $46,83 * * *$ & $85,97^{* *}$ \\
\hline Observações & 57.791 & 16.628 & 4.316 & 18.539 & 5.331 & 12.977 \\
\hline
\end{tabular}

Fonte: Elaboração própria.

Nota: Erros-padrão robustos entre parênteses. *** Significativo a 1\%. ** Significativo a 5\%.

* Significativo a $10 \%$.

Os resultados obtidos para a variável VA Indústria por meio das estimações por Tobit em painel, mostrados na Tabela 6 , garantem robustez à interpretação da existência das relações em formato de um "U-invertido", pois os coeficientes estimados associados ao PIB per capita em nível são todos positivos e significativos (a $1 \%$ ) e os coeficientes associados a esta variável ao quadrado são negativos e significativos (a 1\%). Portanto, assim como no caso das estimações com a participação da indústria no emprego, as estimações com a participação no produto sugerem que a evolução da industrialização nos municípios brasileiros pode ser um processo "natural" atrelado ao desenvolvimento econômico. 
Tabela 6 - Variável dependente VA Indústria: estimações por Tobit em painel

\begin{tabular}{|c|c|c|c|c|c|c|}
\hline $\begin{array}{l}\text { Variável/ } \\
\text { Região }\end{array}$ & Brasil & Sudeste & Norte & Nordeste & $\begin{array}{c}\text { Centro- } \\
\text { Oeste }\end{array}$ & Sul \\
\hline PIB per capita & $\begin{array}{c}1,190 * * * \\
(0,010)\end{array}$ & $\begin{array}{c}0,883 * * * \\
(0,015)\end{array}$ & $\begin{array}{c}4,069 * * * \\
(0,080)\end{array}$ & $\begin{array}{c}2,085^{* * *} \\
(0,032)\end{array}$ & $\begin{array}{c}1,221 * * * \\
(0,043)\end{array}$ & $\begin{array}{c}1,641 * * * \\
(0,026)\end{array}$ \\
\hline PIB per capita ${ }^{2}$ & $\begin{array}{c}-0,005 * * \\
(0,000)\end{array}$ & $\begin{array}{c}-0,003 * * * \\
(0,000)\end{array}$ & $\begin{array}{c}-0,059 * * * \\
(0,002)\end{array}$ & $\begin{array}{c}-0,010 * * * \\
(0,000)\end{array}$ & $\begin{array}{c}-0,009 * * * \\
(0,001)\end{array}$ & $\begin{array}{c}-0,009 * * * \\
(0,000)\end{array}$ \\
\hline Controles & $\operatorname{Sim}$ & Sim & Sim & Sim & Sim & $\operatorname{Sim}$ \\
\hline $\begin{array}{c}\text { Dummies } \\
\text { Anuais }\end{array}$ & Sim & Sim & Sim & Sim & Sim & Sim \\
\hline Constantes & Sim & Sim & Sim & Sim & Sim & Sim \\
\hline Prob $>$ chi $^{2}$ & 0,000 & 0,000 & 0,000 & 0,000 & 0,000 & 0,000 \\
\hline Observações & 57.791 & 16.628 & 4.316 & 18.539 & 5.331 & 12.977 \\
\hline
\end{tabular}

Fonte: Elaboração própria.

Nota: Erros-padrão robustos entre parênteses. ** * Significativo a 1\%. ** Significativo a 5\%.

* Significativo a $10 \%$.

A Tabela 7 mostra os PIBs per capita médios de pontos de máximos, ou seja, os turning points calculados a partir dos coeficientes obtidos nas estimações por efeitos fixos. As comparações desses pontos garantem evidências para averiguar duas hipóteses adicionais. A primeira é a de que, devido à tendência de crescimento mais rápido da produtividade do trabalho na indústria do que em outros setores, a participação industrial no emprego total reduziria "antes" do que a participação no produto, ou seja, em um nível de renda per capita inferior. Os turning points encontrados com os coeficientes estimados corroboram tal hipótese. No Brasil e em todas as suas regiões, na média, as participações industriais no emprego formal passam a diminuir em níveis de PIB per capita inferiores aos dos inícios das reduções das participações industriais no produto. No Sudeste, no Nordeste, no Sul e, em função destes, no país como um todo, comparativamente às demais regiões, os PIBs per capita médios de pontos máximos das participações industriais no produto são bastante superiores aos do emprego.

A segunda hipótese é a de que a retração da participação industrial pode ocorrer em níveis de renda per capita inferiores aos de economias mais desenvolvidas, o que, de acordo com a literatura revisada na segunda seção, se configuraria como uma desindustrialização "precoce" ("prematura"). Como não existe consenso na literatura sobre qual é a renda per capita "ideal" a partir da qual a participação industrial pode cair sem denotar precocidade e, assim, sem ser negativa, os turning points do Sudeste são os parâmetros de comparação, por ser a região com maior consolidação da indústria. Assim, a ideia de precocidade aqui utilizada é apenas em comparação à principal região industrial brasileira. Pela participação 
no emprego, a Tabela 7 mostra que apenas a retração no Norte é precoce, pois é a única região na qual a retração se dá em um PIB per capita médio inferior ao do Sudeste.

Tabela 7 - PIBs per capita médios (R\$ de 2000) nos pontos de máximos (turning points), segundo as variáveis dependentes (estimações com efeitos fixos)

\begin{tabular}{ccc}
\hline Região & Emprego Indústria & VA Indústria \\
\hline Brasil & 64,50 & 112,20 \\
Sudeste & 36,00 & 133,67 \\
Norte & 33,38 & 33,67 \\
Nordeste & 75,50 & 107,00 \\
Centro-Oeste & 61,75 & 69,39 \\
Sul & 55,50 & 90,28 \\
\hline
\end{tabular}

Fonte: Elaboração própria.

Considerando o VA industrial, a retração relativa da indústria ocorre a partir de PIBs per capita médios inferiores ao do Sudeste em todas as demais regiões e, consequentemente, no Brasil. O turning point do Nordeste é o mais próximo ao do Sudeste; os demais são bem inferiores. Portanto, mesmo sendo mais robusta apenas para o Norte, por ser constatada para as duas proxies, as comparações dos turning points não refutam integralmente a hipótese de que os municípios das demais regiões do país sofrem desindustrialização precoce em comparação aos do Sudeste. Essas evidências são consonantes aos resultados de Monteiro e Lima (2014) e de Spíndola e Lima (2015), comentados anteriormente.

Estes mesmos trabalhos, assim como Cruz e Santos (2001), Saboia (2001) e Saboia e Kubrusly (2008), entre outros, apontam evidências que podem justificar o turning point do Sudeste no emprego ser superior apenas ao do Norte, mas bem próximo, e bastante inferior ao seu próprio turning point no produto, sendo a diferença maior do que as diferenças de turning point entre produto e emprego das demais regiões. Como mencionado na terceira seção, no Sudeste, principalmente no estado de São Paulo, ocorreu nas últimas décadas uma maior especialização em atividades industriais com maior conteúdo tecnológico, capital-intensivas e produtividade mais elevadas. Consequentemente, foram desconcentradas regionalmente, pelo menos em parte, atividades industriais mais tradicionais e intensivas em trabalho, que já eram características nas demais regiões. No Norte, há significativa participação da indústria eletroeletrônica, de maior conteúdo tecnológico e capital-intensiva, o que pode explicar a retração da participação no emprego em nível de renda anterior às demais. Porém, nessa região, a participação industrial no produto também possui turning point relativamente baixo. 
Finalmente, as Tabelas 8 e 9 apresentam os resultados das estimações por efeitos fixos que consideram como variáveis dependentes, respectivamente, as razões entre os empregos formais nos serviços e na indústria (Emprego Serviços/ Indústria) e entre os VAs gerados nos serviços e na indústria (VA Serviços/Indústria). Estas variáveis são usadas para avaliar a hipótese de que, ao longo do desenvolvimento, a participação relativa da indústria aumenta até certo estágio, a partir do qual a participação relativa dos serviços se eleva em detrimento à da indústria. Para isso, é aqui proposto que devem ser obtidas relações no formato de "U" entre as variáveis dependentes e o PIB per capita.

Tabela 8 - Variável dependente Emprego Serviços/Indústria: estimações por efeitos fixos

\begin{tabular}{ccccccc}
\hline Variável/Região & Brasil & Sudeste & Norte & Nordeste & $\begin{array}{c}\text { Centro- } \\
\text { Oeste }\end{array}$ & Sul \\
\hline PIB per capita & $-0,025$ & $-0,051^{*}$ & $-0,076$ & $-0,998$ & $-0,043$ & $-0,001$ \\
& $(0,182)$ & $(0,030)$ & $(0,216)$ & $(1,405)$ & $(0,211)$ & $(0,029)$ \\
PIB per capita ${ }^{2}$ & 0,001 & $0,001^{*}$ & 0,001 & 0,005 & 0,001 & 0,001 \\
& $(0,001)$ & $(0,000)$ & $(0,005)$ & $(0,009)$ & $(0,003)$ & $(0,001)$ \\
Controles & Sim & Sim & Sim & Sim & Sim & Sim \\
Dummies Anuais & Sim & Sim & Sim & Sim & Sim & Sim \\
Constantes & Sim & Sim & Sim & Sim & Sim & Sim \\
Prob > F & 0,000 & 0,000 & 0,000 & 0,000 & 0,000 & 0,000 \\
Teste de Hausman & $10,86^{*}$ & $34,78^{*}$ & $18,80^{*}$ & $12,10^{*}$ & $11,21 *$ & $12,26^{*}$ \\
Observações & 57.798 & 16.629 & 4.316 & 18.543 & 5.331 & 12.979 \\
\hline
\end{tabular}

Fonte: Elaboração própria.

Nota: Erros-padrão robustos entre parênteses. *** Significativo a 1\%. ** Significativo a 5\%.

* Significativo a $10 \%$. 
Tabela 9 - Variável dependente VA Serviços/Indústria: estimações por efeitos fixos

\begin{tabular}{|c|c|c|c|c|c|c|}
\hline $\begin{array}{l}\text { Variável/ } \\
\text { Região }\end{array}$ & Brasil & Sudeste & Norte & Nordeste & $\begin{array}{c}\text { Centro- } \\
\text { Oeste }\end{array}$ & Sul \\
\hline PIB per capita & $\begin{array}{c}-0,049^{* * *} \\
(0,013)\end{array}$ & $\begin{array}{c}-0,014^{* * *} \\
(0,004)\end{array}$ & $\begin{array}{c}-2,163^{* * *} \\
(0,339)\end{array}$ & $\begin{array}{c}-0,117^{* * *} \\
(0,015)\end{array}$ & $\begin{array}{c}-0,081 * * * \\
(0,018)\end{array}$ & $\begin{array}{l}-0,007 \\
(0,003)\end{array}$ \\
\hline PIB per capita ${ }^{2}$ & $\begin{array}{c}0,001 * * * \\
(0,000)\end{array}$ & $\begin{array}{c}0,001 * * * \\
(0,000)\end{array}$ & $\begin{array}{c}0,038 * * * \\
(0,008)\end{array}$ & $\begin{array}{c}0,001 * * * \\
(0,000)\end{array}$ & $\begin{array}{c}0,001 * * * \\
(0,000)\end{array}$ & $\begin{array}{c}0,001 \\
(0,000)\end{array}$ \\
\hline Controles & Sim & Sim & Sim & Sim & Sim & Sim \\
\hline $\begin{array}{c}\text { Dummies } \\
\text { Anuais }\end{array}$ & Sim & Sim & Sim & Sim & Sim & Sim \\
\hline Constantes & Sim & Sim & Sim & Sim & Sim & Sim \\
\hline Prob $>F$ & 0,000 & 0,000 & 0,000 & 0,000 & 0,000 & 0,000 \\
\hline $\begin{array}{l}\text { Teste de } \\
\text { Hausman }\end{array}$ & $353,91 * *$ & $246,03 * * *$ & $60,29 * * *$ & $328,37 * * *$ & $41,04 * * *$ & $333,23 * *$ \\
\hline Observações & 57.798 & 16.629 & 4.316 & 18.543 & 5.331 & 12.979 \\
\hline
\end{tabular}

Fonte: Elaboração própria.

Nota: Erros-padrão robustos entre parênteses. ** : Significativo a 1\%. ** Significativo a 5\%.

* Significativo a $10 \%$.

No caso do emprego (Tabela 8), os coeficientes estimados para o Brasil e para todas as regiões apresentam os sinais necessários para não refutar a hipótese: negativos para o PIB per capita em nível e positivos para o PIB per capita ao quadrado. Porém, são significativos somente na estimação para os municípios do Sudeste (e apenas a 10\%). No caso da variável VA Serviços/Indústria (Tabela 9), os coeficientes estimados também apresentam os sinais para corroborar a hipótese aqui proposta de uma relação com o desenvolvimento econômico no formato de em "U": negativo para o PIB per capita em nível e positivo para o PIB per capita ao quadrado. Vale destacar que apenas na estimação para os municípios do Sul os coeficientes não são significativos; nas demais regiões e no Brasil, são a 1\%.

Portanto, considerando os municípios brasileiros no período de 1999 a 2011 , segmentados pelas regiões geográficas, os resultados das estimações realizadas no presente estudo sinalizam evidências que, se não as corroboram com robustez, também não refutam integralmente as hipóteses de que: a relação entre o grau de industrialização e o nível de renda per capita assume o formato de um "U-invertido"; a participação da indústria no emprego diminui a partir de um nível de renda per capita inferior ao do início da retração da participação industrial no produto; e que o setor de serviços tende a ganhar maior importância relativa em detrimento à importância da indústria. A convergência desses aspectos sugere que, nos municípios do país, a desindustrialização pode ser, ao menos em algum grau, um processo "natural" influenciado pela dinâmica do desenvolvimento econômico. 
Por outro lado, podem ser precoces as reduções das participações industriais no produto em municípios das demais regiões em comparação aos da região Sudeste (turning points em PIBs per capita médios inferiores).

\section{Considerações Finais}

O problema da desindustrialização tem sido bastante discutido pela literatura nos seus diversos conceitos e causas: seja um resultado do desenvolvimento econômico, como um processo "natural" em que ocorre avanço do setor de serviços em relação à indústria à medida em que se atinge patamares mais elevados de renda per capita; seja como um processo "induzido" por políticas macroeconômicas liberalizantes ou por uma "doença holandesa". O presente estudo insere-se nesse debate averiguando a hipótese de desindustrialização "natural". A revisão da literatura empírica e as análises descritivas realizadas não refutam a hipótese para as regiões brasileiras. Mais importante ainda, as estimações econométricas com dados municipais em painel (por efeitos fixos e pelo método Tobit) referentes ao período de 1999 a 2011 testam relações condicionadas entre as participações industriais no emprego e no produto e o PIB per capita, avaliando se estas assumem o formato de um "U-invertido", como é defendido pela literatura econômica para a caracterização como desindustrialização "natural". A literatura levanta, ainda, outras hipóteses inter-relacionadas à do "U-invertido", que foram apontadas na introdução. Este estudo também se propôs a testá-las. Entre os resultados obtidos, destacam-se:

(i) formato de um "U-invertido" para as relações entre as participações industriais no emprego e no produto e o PIBs per capita, tanto no Brasil como em todas as suas regiões geográficas;

(ii) redução da participação industrial no emprego em nível de renda per capita inferior à da queda da participação industrial no produto para o Brasil e suas regiões, o que pode refletir a tendência de crescimento mais rápido da produtividade do trabalho na indústria do que em outros setores;

(iii) diminuições das participações relativas da indústria, especialmente no caso do produto, para as regiões brasileiras relativamente menos desenvolvidas em níveis de renda per capita (turning points) inferiores aos valores observados para a região Sudeste (mais desenvolvida), o que, com análises adicionais, pode sinalizar uma precocidade da desindustrialização nas primeiras;

(iv) redução da importância relativa da produção industrial em relação ao setor de serviços a partir de certo nível de renda per capita em quase todas as regiões (exceto a Sul) e no Brasil. 
A convergência destas evidências não refuta a hipótese de a desindustrialização nos municípios brasileiros ser um processo "natural" associado ao desenvolvimento econômico (ou crescimento), mensurado pela dinâmica da renda per capita. Por se tratar de uma análise comparativa de diferentes municípios, nada impede que, no todo, o país esteja sofrendo um processo de desindustrialização por qualquer causa, seja também "natural" ou seja "induzida" por "doença holandesa" ou por políticas macroeconômicas, ou até mesmo que não esteja sofrendo desindustrialização. Chama a atenção, no entanto, a possibilidade de a desindustrialização ocorrer de forma precoce (prematura) em algumas regiões, o que pode limitar o crescimento econômico no longo prazo. O presente estudo somente apresentou algumas evidências que podem sinalizar tal possibilidade. Este é um aspecto que merece preocupação e que pode motivar trabalhos futuros que avaliem especificamente se as reduções das participações da indústria no emprego e, principalmente, no produto das demais regiões em níveis de renda per capita municipais inferiores aos do Sudeste representam processos negativos à economia. Trabalhos futuros também podem tentar explicar melhor os diferentes turning points regionais.

Por fim, é importante destacar que, além dos resultados obtidos, este estudo traz contribuições inovadoras para o debate acerca da desindustrialização no Brasil em termos de estratégias empíricas, em especial para testar as hipóteses inter-relacionadas e associadas à ideia de um processo "natural" atrelado ao desenvolvimento. Ao contrário dos poucos trabalhos existentes, são utilizados dados em painel para todos os municípios brasileiros e para doze anos. Ademais, são controladas características municipais observadas e não observadas (efeitos fixos) que refletem disparidades locacionais que podem afetar o grau de industrialização, assim como efeitos fixos temporais. Vale menção, ainda, à realização de estimações adicionais pelo método Tobit em painel para testar a robustez dos resultados frente à censura de dados nas variáveis dependentes, e o emprego como variáveis dependentes de indicadores aqui calculados que representam a importância dos serviços relativamente à industrial.

\section{Referências}

AZEVEDO, P. F.; TONETO JÚNIOR, R. Relocalização do emprego industrial formal no Brasil na década de 90. Pesquisa e Planejamento Econômico, v. 31, n. 1, p. 153-186, abr. 2001.

BALTAGI, B. H. Econometric analysis of panel data. New Jersey: Wiley and Sons, 2001.

BARBOSA, W.; CARMO, A. S. S.; RAHIER, A. P. Existe desindustrialização no Estado do Paraná? Um teste empírico para o período de 1996 a 2012. Informe Gepec, Toledo, v. 19, n. 1, p. 55-79, jan./jun. 2015. 
BONELLI, R. Industrialização e desenvolvimento: notas e conjecturas com foco na experiência do Brasil. In: SEMINÁRIO INDUSTRIALIZAÇÃO, DESINDUSTRIALIZAÇÃO E DESENVOLVIMENTO, FIESP, IEDI. São Paulo, nov. 2005.

BOTELHO, M. R. A.; SOUSA, G. F.; AVELLAR, A. P. M. A incidência desigual do processo de desindustrialização nos estados brasileiros. In: SEMINÁRIO SOBRE A ECONOMIA MINEIRA DE DIAMANTINA, 16., 2014. Anais eletrônicos... Diamantina: UFMG, 2014.

BRASIL. Ministério do Trabalho e Emprego. Relação Anual de Informações Sociais (RAIS)., Brasília, DF: MTE, 1999 a 2011.

BRESSER-PEREIRA, L. C. The Dutch disease and its neutralization: a Ricardian approach. Revista de Economia Política, v. 28, n. 1, p. 47-71, 2007.

CAÇADOR, S. B. A economia do Espírito Santo está passando por um processo de desindustrialização? Redes (St. Cruz Sul, Online), v. 20, nº 3, suplemento, p. 341-362, set./ dez. 2015.

CAMERON, A. C.; TRIVEDI, P. K. Microeconometrics using Stata. College Station, TX: Stata Press, 2009.

CANO, W. A desindustrialização no Brasil. Economia e Sociedade, Campinas, v. 21, n. especial, p. 831-851, dez. 2012.

CANO, W. Auge e inflexão da desconcentração econômica regional. In: AFFONSO, R. B. A.; SILVA, P. L. B. (Ed.). A Federação em perspectiva: ensaios selecionados. São Paulo: Hucitec, Abet, 1997a.

. Concentração e desconcentração econômica regional no Brasil. Economia e Sociedade, v. 6, n. 1, p. 101-141, jun. 1997b.

. Desequilíbrios regionais e concentração industrial no Brasil - 1930/1970. 1981. Tese (Livre docência), Universidade Estadual de Campinas, Campinas, 1981. 1977.

. Raízes da concentração industrial de São Paulo. São Paulo: Difusão Europeia do Livro,

CARVALHO, L.; KUPFER, D. A transição estrutural da indústria brasileira: da diversificação para a especialização. In: ENCONTRO NACIONAL DE ECONOMICA DA ANPEC, 35., 2007. Anais eletrônicos..., Recife: ANPEC, 2007.

CLARK, C. The conditions of economic progress. London: Macmillan, 1957.

CRUZ, B. O.; SANTOS, I. R. S. Dinâmica do emprego industrial no Brasil entre 1990 e 2009: uma visão regional da desindustrialização. Rio de Janeiro: IPEA, 2011. (Texto para discussão, n. 1673).

FAGUNDO, L. M. C. A indústria na região metropolitana de São Paulo: há um processo recente de desindustrialização? 2008. Dissertação (Mestrado em Economia Política) Pontifícia Universidade Católica de São Paulo, São Paulo, 2008. 
FEIJÓ, C. A.; CARVALHO, P. G. M.; ALMEIDA, J. S. G. Ocorreu uma desindustrialização no Brasil? São Paulo: IEDI, 2005.

GREENE, W. H. Econometric Analysis. 3. ed. New Jersey: Prentice Hall, 1997.

IBGE. Produto Interno Bruto dos Municípios. Rio de Janeiro: IBGE, 1999 a 2011.

KALDOR, N. Causes of the slow rate of economic growth of the United Kingdom: an inaugural lecture. Cambridge: Cambridge University Press, 1966.

MARGARIDO, M.; SERIGATI, F.; PEROSA, B. B. Preços internacionais de commodities e taxa de câmbio real. In: BRITTO, M. H.; NAKANO, Y. (Org.). Taxa de Câmbio no Brasil: estudos de uma perspectiva do desenvolvimento econômico. Rio de Janeiro: Campus, 2011.

MONTEIRO, F. D. S. C.; LIMA, J. P. R. Desindustrialização regional no Brasil. In: ENCONTRO PERNAMBUCANO DE ECONOMIA, 3., 2014. Anais... Recife: UFPE, nov. 2014.

NAKAHODO, S. N.; JANK, M. S. A falácia da doença holandesa. São Paulo: Instituto de Estudos do Comércio e Negociações Internacionais, 2006.

NASSIF, A. Há evidências de desindustrialização no Brasil? Brazilian Journal of Political Economy, v. 28, n. 1, p. 72-96, jan./mar. 2008.

NUNES, S. F.; CASONATO, L. COSTA, V. B. A indústria no governo Lula: um enfoque sobre o possível processo de desindustrialização. A Economia em Revista, v. 22, n. 1, p. 53-65, jul. 2014.

OREIRO, J. L.; FEIJÓ, C. A. Desindustrialização: Conceituação, causas, efeitos e o caso brasileiro. Revista de Economia Política, v. 30, n. 2, p. 219-232, abr./jun. 2010.

OXLEY, H.; MARTIN, J. P. Controlling government spending and deficit: trends in the 1980s and prospects for the 1990s. OECD Economic Studies, n. 17, 1991.

PALMA, J. G. Quatro fontes de "desindustrialização" e um novo conceito de "doença holandesa”. In: CONFERÊNCIA INDUSTRIALIZAÇÃO, DESINDUSTRIALIZAÇÃO E DESENVOLVIMENTO. Anais... São Paulo: FIESP e IEDI, ago. 2005.

RAMOS, R. A. R. Localização industrial: um modelo espacial para o Noroeste de Portugal. 2000. Tese (Doutorado em Engenharia Civil) - Universidade do Minho, Braga, 2000.

RODRIK, D. Premature Deindustrialization. Cambridge: NBER, Feb. 2014. (NBER Working Paper, n. 20.935).

ROWTHORN, R.; RAMASWAMY, R. Deindustrialization: Causes and implications. Washington: International Monetary Fund, Apr. 1997. (Working Paper/97/42).

ROWTHORN, R; WELLS, J. R. De-industrialization and foreign trade. Cambridge: Cambridge University Press, 1987.

SABOIA, J. Descentralização industrial no Brasil na década de noventa: um processo dinâmico e diferenciado regionalmente. Nova Economia, v. 11, n. 2, p. 85-122, dez. 2001. 
SABOIA, J.; KUBRUSLY, L. Diferenciais regionais e setoriais na indústria brasileira. Economia Aplicada, v. 12, n.1, p. 125-149, jan./mar. 2008

SAIANI, C. C. S.; PEROSA, B. B. Industrialização, distribuição de renda e desenvolvimento econômico: algumas evidências para os municípios brasileiros. In: VIEIRA, F. V. (Org.). Indústria, crescimento e desenvolvimento. Campinas: Alínea, 2014.

SILVA, A. N. Análise da desindustrialização no Rio Grande do Sul - 1995-10. 2013. Dissertação (Mestrado em Economia) - Faculdade de Administração, Contabilidade e Economia, Pontifícia Universidade Católica do Rio Grande do Sul, Porto Alegre, 2013.

SILVA, R. D. Desconcentração, desindustrialização e transformações produtivas na Região Metropolitana do Rio de Janeiro no pós 1990. In: SEMINARIO INTERNACIONAL DE LA RED IBEROAMERICANA DE INVESTIGADORES SOBRE GLOBALIZACIÓN Y TERRITORIO, 11., 2010. Anais... Mendoza: Universidad Nacional de Cuyo, 2010.

SPÍNDOLA, F. D.; LIMA, J. P. Desindustrialização regional no Brasil. In: CONGRESS OF THE EUROPEAN REGIONAL SCIENCE ASSOCIATION: "WORLD RENAISSANCE: CHANGING ROLES FOR PEOPLE AND PLACES”, 55., 2015. Anais... Lisbon: ERSA, Aug. 2015, p. 25-28SZIRMAI, A.; VERSPAGEN, B. Manufacturing and Economic Growth in Developing Countries, 1950-2005. Maastricht: UNU-MERIT, Dec. 2011. (UNU-MERIT Working Papers 2011-069).

TREGENNA, F. Characterizing deindustrialization: an analysis of changes in manufacturing employment and output internationally. Cambridge Journal of Economics, v. 33, n. 3, p. 433466, 2009.

. Deindustrialisation, Structural Change and Sustainable Economic Growth. Vienna: UNIDO, 2015. (Working Paper 2/2015).

WOOLDRIDGE, J. M. Introductory Econometrics. 20. ed., São Paulo: Thomson Learning, 2002 .

\section{Apêndice A - Título Resultados Complementares das Estimações: Coeficien- tes das Covariadas}

Tabela 10 - Resultados das covariadas: complemento da Tabela 3

\begin{tabular}{ccccccc}
\hline $\begin{array}{c}\text { Variável/ } \\
\text { Região }\end{array}$ & Brasil & Sudeste & Norte & Nordeste & $\begin{array}{c}\text { Centro- } \\
\text { Oeste }\end{array}$ & Sul \\
\hline \multirow{2}{*}{ População } & $-0,018^{* * *}$ & $-0,013^{* * *}$ & 0,003 & $-0,016^{* * *}$ & $-0,014$ & $-0,036^{* * *}$ \\
& $(0,003)$ & $(0,003)$ & $(0,010)$ & $(0,005)$ & $(0,015)$ & $(0,011)$ \\
\multirow{2}{*}{ Formalização } & $0,261^{* * *}$ & $0,246^{* * *}$ & $-0,182^{* * *}$ & $0,260 * * *$ & $0,385^{* * *}$ & $0,364^{* * *}$ \\
& $(0,007)$ & $(0,010)$ & $(0,042)$ & $(0,014)$ & $(0,025)$ & $(0,014)$ \\
\multirow{2}{*}{ Fundamental } & $0,020^{* * *}$ & $0,077^{* * *}$ & 0,011 & $-0,008$ & $0,061^{* * *}$ & $0,042^{* * *}$ \\
& $(0,005)$ & $(0,011)$ & $(0,019)$ & $(0,006)$ & $(0,023)$ & $(0,015)$ \\
\hline & & & & & & Continua $\ldots$
\end{tabular}




\begin{tabular}{ccccccc}
$\begin{array}{c}\text { Variável/ } \\
\text { Região }\end{array}$ & Brasil & Sudeste & Norte & Nordeste & $\begin{array}{c}\text { Centro- } \\
\text { Oeste }\end{array}$ & Sul \\
\hline Morbidade & $-0,019^{*}$ & $0,116^{* * *}$ & $-0,044$ & $-0,056^{* * *}$ & $-0,110^{* *}$ & $-0,010$ \\
& $(0,011)$ & $(0,021)$ & $(0,042)$ & $(0,018)$ & $(0,043)$ & $(0,022)$ \\
Bens & 0,000 & 0,000 & 0,000 & 0,001 & 0,000 & 0,000 \\
Econômicos & $(0,000)$ & $(0,000)$ & $(0,001)$ & $(0,000)$ & $(0,001)$ & $(0,000)$ \\
& $-0,002 * * *$ & 0,001 & 0,001 & $-0,017^{* * *}$ & $-0,008^{* * *}$ & $-0,030^{* * *}$ \\
IPTU & $(0,000)$ & $(0,001)$ & $(0,001)$ & $(0,002)$ & $(0,003)$ & $(0,003)$ \\
& $-0,297^{* * *}$ & $-0,395^{* * *}$ & $-0,144^{* * *}$ & $-0,197 * * *$ & $-0,404^{* * *}$ & $-0,550 * * *$ \\
Emprego & $(0,004)$ & $(0,008)$ & $(0,016)$ & $(0,006)$ & $(0,015)$ & $(0,012)$ \\
\hline
\end{tabular}

Fonte: Elaboração própria.

Nota: Erros-padrão robustos entre parênteses. * * Significativo a 1\%. ** Significativo a 5\%.

* Significativo a $10 \%$.

Tabela 11 - Resultados das covariadas: complemento da Tabela 4

\begin{tabular}{ccccccc}
\hline $\begin{array}{c}\text { Variável/ } \\
\text { Região }\end{array}$ & Brasil & Sudeste & Norte & Nordeste & $\begin{array}{c}\text { Centro- } \\
\text { Oeste }\end{array}$ & Sul \\
\hline População & $-0,004 * *$ & $-0,003 * * *$ & $0,013 * *$ & 0,003 & $-0,019 * * *$ & $-0,022 * * *$ \\
& $(0,001)$ & $(0,001)$ & $(0,006)$ & $(0,003)$ & $(0,007)$ & $(0,005)$ \\
Formalização & $0,375 * * *$ & $0,296 * * *$ & $-0,084$ & $0,442 * * *$ & $0,415 * * *$ & $0,458 * * *$ \\
& $(0,008)$ & $(0,010)$ & $(0,005)$ & $(0,002)$ & $(0,002)$ & $(0,001)$ \\
Fundamental & $0,037 * *$ & $0,096 * * *$ & 0,038 & $-0,015^{*}$ & $0,067 * * *$ & $0,073 * * *$ \\
& $(0,006)$ & $(0,011)$ & $(0,028)$ & $(0,009)$ & $(0,024)$ & $(0,015)$ \\
Morbidade & 0,003 & $0,112 * * *$ & 0,034 & $-0,024$ & $-0,092 * *$ & $-0,010$ \\
Bens & $(0,012)$ & $(0,021)$ & $(0,052)$ & $(0,024)$ & $(0,044)$ & $(0,022)$ \\
Econômicos & 0,000 & 0,000 & 0,000 & 0,000 & 0,001 & 0,000 \\
IPTU & $(0,000)$ & $(0,000)$ & $(0,001)$ & $(0,001)$ & $(0,001)$ & $(0,000)$ \\
& $-0,004 * * *$ & 0,000 & 0,001 & $-0,027 * * *$ & $-0,011 * * *$ & $-0,032 * * *$ \\
Emprego & $(0,001)$ & $(0,001)$ & $(0,002)$ & $(0,003)$ & $(0,003)$ & $(0,003)$ \\
Agropecuária & $-0,356 * * *$ & $-0,394 * * *$ & $-0,199 * * *$ & $-0,268 * * *$ & $-0,452 * * *$ & $-0,566 * * *$ \\
\hline
\end{tabular}

Fonte: Elaboração própria.

Nota: Erros-padrão robustos entre parênteses. ** Significativo a 1\%. ** Significativo a 5\%.

* Significativo a $10 \%$. 
Tabela 12 - Resultados das covariadas: complemento da Tabela 5

\begin{tabular}{ccccccc}
\hline $\begin{array}{c}\text { Variável/ } \\
\text { Região }\end{array}$ & Brasil & Sudeste & Norte & Nordeste & $\begin{array}{c}\text { Centro- } \\
\text { Oeste }\end{array}$ & Sul \\
\hline População & $-0,004 *$ & $-0,007 * *$ & 0,004 & 0,000 & $0,017 * *$ & 0,006 \\
& $(0,002)$ & $(0,003)$ & $(0,006)$ & $(0,003)$ & $(0,008)$ & $(0,008)$ \\
Formalização & $0,096^{* * *}$ & $0,090^{* * *}$ & $0,050^{* *}$ & $0,113^{* * *}$ & 0,018 & 0,013 \\
& $(0,005)$ & $(0,009)$ & $(0,023)$ & $(0,009)$ & $(0,014)$ & $(0,010)$ \\
Fundamental & $0,014^{* * *}$ & $0,020^{*}$ & $0,022^{* *}$ & $0,007 *$ & 0,019 & $0,037 * *$ \\
& $(0,003)$ & $(0,010)$ & $(0,011)$ & $(0,004)$ & $(0,013)$ & $(0,010)$ \\
Morbidade & $-0,049 * *$ & $-0,056^{* * *}$ & $-0,035$ & $-0,095 * * *$ & 0,019 & 0,013 \\
Bens & $(0,008)$ & $(0,020)$ & $(0,023)$ & $(0,011)$ & $(0,024)$ & $(0,015)$ \\
Econômicos & 0,000 & 0,000 & 0,000 & 0,000 & $-0,001 *$ & 0,000 \\
IPTU & $(0,000)$ & $(0,000)$ & $(0,000)$ & $(0,000)$ & $(0,000)$ & $(0,000)$ \\
& 0,000 & $-0,001$ & 0,000 & $0,004 * *$ & 0,001 & $-0,019 * * *$ \\
VA Agrope- & $-0,334 * *$ & $-0,335^{* * *}$ & $-0,406 * * *$ & $-0,266 * *$ & $-0,443 * * *$ & $-0,426 * * *$ \\
cuária & $(0,003)$ & $(0,007)$ & $(0,009)$ & $(0,005)$ & $(0,010)$ & $(0,007)$ \\
\hline
\end{tabular}

Fonte: Elaboração própria.

Nota: Erros-padrão robustos entre parênteses. * * Significativo a 1\%. ** Significativo a 5\%.

* Significativo a $10 \%$.

Tabela 13 - Resultados das covariadas: complemento da Tabela 6

\begin{tabular}{ccccccc}
\hline $\begin{array}{c}\text { Variável/ } \\
\text { Região }\end{array}$ & Brasil & Sudeste & Norte & Nordeste & $\begin{array}{c}\text { Centro- } \\
\text { Oeste }\end{array}$ & Sul \\
\hline \multirow{2}{*}{ População } & $-0,003^{* * *}$ & $-0,002 * * *$ & $-0,006^{* *}$ & $-0,003 * *$ & $-0,008^{*}$ & $-0,013^{* * *}$ \\
& $(0,001)$ & $(0,001)$ & $(0,003)$ & $(0,001)$ & $(0,004)$ & $(0,003)$ \\
Formalização & $0,119 * * *$ & $0,103 * *$ & 0,030 & $0,133 * * *$ & 0,006 & $0,061 * * *$ \\
& $(0,005)$ & $(0,008)$ & $(0,022)$ & $(0,009)$ & $(0,013)$ & $(0,009)$ \\
Fundamental & $0,018 * * *$ & $0,026^{* *}$ & $0,019 *$ & $0,007 *$ & 0,012 & $0,051^{* * *}$ \\
& $(0,003)$ & $(0,010)$ & $(0,010)$ & $(0,004)$ & $(0,013)$ & $(0,010)$ \\
Morbidade & $-0,049 * * *$ & $-0,072 * * *$ & $-0,035$ & $-0,095 * * *$ & 0,014 & 0,004 \\
Bens & $(0,008)$ & $(0,020)$ & $(0,022)$ & $(0,011)$ & $(0,024)$ & $(0,015)$ \\
Econômicos & 0,000 & 0,000 & 0,000 & 0,000 & $-0,001 *$ & 0,000 \\
& $(0,000)$ & $(0,000)$ & $(0,000)$ & $(0,000)$ & $(0,000)$ & $(0,000)$ \\
IPTU & $-0,001 * *$ & $-0,001 * *$ & 0,000 & 0,002 & 0,000 & $-0,022 * * *$ \\
& $(0,000)$ & $(0,001)$ & $(0,001)$ & $(0,002)$ & $(0,002)$ & $(0,002)$ \\
\hline & & & & & & continua...
\end{tabular}


conclusão.

\begin{tabular}{ccccccc}
\hline $\begin{array}{c}\text { Variável/ } \\
\text { Região }\end{array}$ & Brasil & Sudeste & Norte & Nordeste & $\begin{array}{c}\text { Centro- } \\
\text { Oeste }\end{array}$ & Sul \\
\hline VA & $-0,343^{* * *}$ & $-0,352^{* * *}$ & $-0,398^{* * *}$ & $-0,273^{* * *}$ & $-0,454^{* * *}$ & $-0,446^{* * *}$ \\
Agropecuária & $(0,003)$ & $(0,006)$ & $(0,009)$ & $(0,005)$ & $(0,009)$ & $(0,006)$ \\
\hline
\end{tabular}

Fonte: Elaboração própria.

Nota: Erros-padrão robustos entre parênteses. * * Significativo a 1\%. ** Significativo a 5\%.

* Significativo a $10 \%$.

Tabela 14 - Resultados das covariadas: complemento da Tabela 8

\begin{tabular}{ccccccc}
\hline $\begin{array}{c}\text { Variável/ } \\
\text { Região }\end{array}$ & Brasil & Sudeste & Norte & Nordeste & $\begin{array}{c}\text { Centro- } \\
\text { Oeste }\end{array}$ & Sul \\
\hline População & $-0,032$ & 0,002 & $-0,002$ & $-0,192$ & $-0,021$ & 0,010 \\
& $(0,032)$ & $(0,005)$ & $(0,013)$ & $(0,126)$ & $(0,036)$ & $(0,008)$ \\
Formalização & $2,543 * * *$ & $0,257 * * *$ & $0,213^{* * *}$ & $13,712 * * *$ & $1,195 * * *$ & $0,030 * *$ \\
& $(0,089)$ & $(0,017)$ & $(0,063)$ & $(0,415)$ & $(0,063)$ & $(0,011)$ \\
Fundamental & $-0,142 *$ & $-0,011$ & $-0,013$ & $-0,224$ & $-0,155 * *$ & $-0,021 *$ \\
& $(0,074)$ & $(0,020)$ & $(0,034)$ & $(0,199)$ & $(0,062)$ & $(0,011)$ \\
Morbidade & $-0,104$ & $-0,041$ & $-0,044$ & $-0,499$ & $0,194 *$ & $-0,006$ \\
Bens & $(0,146)$ & $(0,038)$ & $(0,059)$ & $(0,523)$ & $(0,110)$ & $(0,016)$ \\
Econômicos & 0,000 & 0,000 & 0,000 & 0,000 & 0,001 & 0,000 \\
& $(0,000)$ & $(0,000)$ & $(0,002)$ & $(0,013)$ & $(0,002)$ & $(0,000)$ \\
IPTU & $-0,023 * * *$ & $-0,002 * *$ & 0,005 & $-0,491 * *$ & $-0,010$ & $-0,000$ \\
& $(0,007)$ & $(0,001)$ & $(0,005)$ & $(0,064)$ & $(0,007)$ & $(0,002)$ \\
Emprego & $-0,046$ & $-0,093 * * *$ & 0,001 & $-0,601 * * *$ & 0,041 & 0,002 \\
Agropecuária & $(0,062)$ & $(0,014)$ & $(0,030)$ & $(0,203)$ & $(0,041)$ & $(0,010)$ \\
\hline
\end{tabular}

Fonte: Elaboração própria.

Nota: Erros-padrão robustos entre parênteses. ** Significativo a 1\%. * Significativo a 5\%.

* Significativo a $10 \%$. 
Tabela 15 - Resultados das covariadas: complemento da Tabela 9

\begin{tabular}{ccccccc}
\hline $\begin{array}{c}\text { Variável/ } \\
\text { Região }\end{array}$ & Brasil & Sudeste & Norte & $\begin{array}{c}\text { Nordes- } \\
\text { te }\end{array}$ & $\begin{array}{c}\text { Centro- } \\
\text { Oeste }\end{array}$ & Sul \\
\hline \multirow{2}{*}{ População } & $0,008 * * *$ & $0,002 * * *$ & $0,055^{* *}$ & $0,009 * * *$ & $0,008 * *$ & 0,004 \\
& $(0,002)$ & $(0,001)$ & $(0,023)$ & $(0,001)$ & $(0,003)$ & $(0,003)$ \\
Formalização & $-0,012 * *$ & $-0,023 * * *$ & 0,012 & $-0,018^{* * *}$ & $-0,017 * * *$ & 0,002 \\
& $(0,006)$ & $(0,002)$ & $(0,092)$ & $(0,004)$ & $(0,005)$ & $(0,004)$ \\
Fundamental & 0,001 & $-0,015 * * *$ & 0,023 & $-0,002$ & $-0,020 * * *$ & $-0,016 * * *$ \\
& $(0,004)$ & $(0,003)$ & $(0,042)$ & $(0,002)$ & $(0,005)$ & $(0,004)$ \\
Morbidade & $0,027 * *$ & $-0,006$ & $0,243 * * *$ & $-0,004$ & $-0,002$ & $-0,008$ \\
Bens & $(0,009)$ & $(0,005)$ & $(0,092)$ & $(0,005)$ & $(0,009)$ & $(0,005)$ \\
Econômicos & 0,000 & 0,000 & 0,000 & 0,000 & $0,001 * * *$ & 0,000 \\
& $(0,000)$ & $(0,000)$ & $(0,002)$ & $(0,000)$ & $(0,000)$ & $(0,000)$ \\
IPTU & 0,000 & 0,000 & 0,000 & $0,001 * *$ & $-0,001 *$ & $0,004 * * *$ \\
VA & $(0,000)$ & $(0,000)$ & $(0,002)$ & $(0,001)$ & $(0,001)$ & $(0,001)$ \\
Agropecuária & $0,058 * * *$ & $0,044 * * *$ & $0,235 * *$ & $0,035 * *$ & $0,028 * * *$ & $0,025 * * *$ \\
\hline
\end{tabular}

Fonte: Elaboração própria.

Nota: Erros-padrão robustos entre parênteses. ** Significativo a 1\%. ** Significativo a 5\%.

* Significativo a $10 \%$.

Recebido em: 27/09/2016. Aceito em: 01/03/2017. 